\title{
High undescribed diversity of Amanita section Vaginatae in northern Thailand
}

\author{
Thongbai $\mathrm{B}^{1,2}$, Hyde $\mathrm{KD}^{1}$, Lumyong $\mathrm{S}^{3,4}$, Raspé $\mathrm{O}^{5,6 *}$
}

${ }^{1}$ Centre of Excellence in Fungal Research, and School of Science, Mae Fah Luang University, Chiang Rai 57100, Thailand.

${ }^{2}$ Helmholtz-Center for Infection Research, Microbial Drugs Department, Inhoffenstrasse 7, 38124 Braunschweig, Germany.

${ }^{3}$ Department of Biology, Faculty of Science, Chiang Mai University, Chiang Mai 50200, Thailand.

${ }^{4}$ The Center of Excellence in Bioresources for Agriculture, Industry and Medicine, Faculty of Science, Chiang Mai University, Chiang Mai, Thailand.

${ }^{5}$ Botanic Garden Meise, Nieuwelaan 38, 1860 Meise, Belgium.

${ }^{6}$ Fédération Wallonie-Bruxelles, Service général de l'Enseignement universitaire et de la Recherche scientifique, Rue A. Lavallée 1, 1080 Bruxelles, Belgium.

Thongbai B, Hyde KD, Lumyong S, Raspé O 2018 - High undescribed diversity of Amanita section Vaginatae in northern Thailand. Mycosphere 9(3), 462-494, Doi 10.5943/mycosphere/9/3/3

\begin{abstract}
Amanita sect. Vaginatae is the most speciose section of Amanita subg. Amanita. However, to date only three species belonging to this section have been reported from northern Thailand. Here, we report on the study of Amanita sect. Vaginatae specimens collected in the years of 2012 to 2016. Remarkably, all fifteen specimens studied belong to nine species new to science, which were identified based on morphology and DNA sequence analyses of $\beta$-tubulin, nrLSU, nrITS, and $r p b 2$ gene. Those nine species are fully described and illustrated with line drawings and color photographs. Morphological characteristics of related taxa are compared and discussed, and a dichotomous key of Amanita sect. Vaginatae in Thailand is provided.
\end{abstract}

Key words - Amanitaceae - classification - distribution - ectomycorrhizal fungi South-East Asia

\section{Introduction}

Two large monophyletic groups have been consistently identified in the genus Amanita, which correspond to subgenera Amanita and Lepidella (J.E. Gilbert) Beauseign. These are distinguished on the basis of the reaction, or absence thereof, of the basidiospores to iodine solution (Weiß et al. 1998, Drehmel et al. 1999, Zhang et al. 2004, Wolfe et al. 2012). Amanita subg. Amanita is characterized by inamyloid basidiospores and is currently comprised of three sections: Amanita, Caesareae Singer, and Vaginatae sensu Zhu L. Yang (1997). Among the three sections, sect. Vaginatae includes the highest number of taxa, with approximately 281 taxa, while the entire genus Amanita has been estimated to contain 900-950 taxa worldwide (www.amanitaceae.org/?Genus+Amanita, Tulloss \& Yang 2018). Notably, many taxa are not validly published and/or may be synonymous with previously published taxa, and in need of revision (www.amanitaceae.org/?Genus+Amanita, Tulloss \& Yang 2018). 
Sect. Vaginatae, typified by A. vaginata (Bull.) Lam, is characterized by having a bulbless stipe, striate pileus margin as well as most of them lack of a partial veil on the stipe. Micromorphological features include infrequent clamp connections at the base of basidia and globose, subglobose to ellipsoid basidiospores (Bas 1977, Tulloss 1994, Neville \& Poumarat 2009). Recently, several studies have documented new species as well as first records of known Amanita spp. from northern Thailand ( $\mathrm{Li}$ et al. 2016, Thongbai et al. 2016, 2017). In recent intensive mushroom biodiversity exploration, a large number of species belonging to Amanita sect. Vaginatae have been discovered. However, to date, only a few species have been reported and described, i.e. A. aff. angustilamellata Höhn., A. ovalispora Boedijn, and A. pudibunda R. Heim (Sanmee et al. 2008). This study aims to examine new species of Amanita sect. Vaginatae that were discovered in Chiang Mai, Chiang Rai, and Lampang Provinces of northern Thailand in forests dominated by Fagaceae (Castanopsis, Lithocarpus, and Quercus) and/or Dipterocarpaceae (Dipterocarpus and Shorea). A combination of morphological methods and multi-gene phylogenetic analyses include $\beta$-tubulin, nrITS, and $r p b 2$ were used.

\section{Material and methods}

\section{Collections}

Specimens were collected mainly in forests dominated by Fagaceae (Castanopsis, Lithocarpus, and Quercus) and/or Dipterocarpaceae (Dipterocarpus and Shorea) during the rainy season of years 2012-2016. Fresh specimens were photographed and described, and tissue samples were taken with aseptic technique and kept in 10\% CTAB (cetyl trimethylammonium bromide) for later DNA analyses. The specimens were then dried using a food dehydrator (at ca. $40-50^{\circ} \mathrm{C}$ ). The examined specimens were deposited in either one or two of the following herbaria: Mae Fah Luang University, Thailand (MFLU) and Biotec, Thailand (BBH). Herbarium codes follow Index Herbariorum (Thiers 2017), with the exception of "RET", which is the code adopted for R.E. Tulloss' Herbarium Rooseveltensis Amanitorum. All author citations of species rank not included in the main body of the text are located in Table 1.

\section{Morphological study}

Macro-morphological characteristics were described from fresh specimens. Color codes are according to Kornerup \& Wanscher (1978). Microscopic features were studied from dried tissue mounted in $\mathrm{H}_{2} \mathrm{O}$ and $5 \% \mathrm{KOH}$. Congo red was used for highlighting all tissues, and amyloidity of basidiospores was observed using Melzer's reagent. Dimensions of microscopic characters were measured using Image Frame Work (Tarosoft ${ }^{\circledR}$, Thailand). In the description of basidiospore measurements, the following notation was used: "[n/m/p]" indicating that $n$ basidiospores were measured from $m$ basidiomata of $p$ collections with a minimum of 25 basidiospores from each basidiome. Size and shape of basidiospores are presented in a form following the description of ranges for biometric variables according to Tulloss (2018) $(a-) b-c(-d)$, in which $b$ represents the $5^{\text {th }}$ percentile, $c$ represents the $95^{\text {th }}$ percentile, while $a$ and $d$ are the lowest and highest extreme values measured, respectively. The range of length/width ratio of basidiospores $(\mathrm{Q})$ is provided. In addition to Tulloss' standard format, standard deviation are provided for Q' (the mean of all Q values computed for a single taxon). The average length is indicated as $\mathrm{L}^{\prime}$ whereas $\mathrm{W}^{\prime}$ is the average width. Striations on pileus, and especially their length, are important to be recorded. Striations length is expressed as a proportion of the pileus radius (R). Size of basidiomata were described as small, medium, or large (pileus diameter $<50 \mathrm{~mm}, \geq 50-100 \mathrm{~mm}$, or $>100 \mathrm{~mm}$, respectively). Faces of Fungi (Jayasiri et al. 2015) and MycoBank (www.mycobank.org) numbers are provided.

\section{DNA isolation, amplification and DNA sequencing}

Specimens were processed for molecular analyses at core facilities at Botanic Garden Meise, Belgium, using a variety of methodologies for extraction of genomic DNA, PCR and sequencing. 
Genomic DNA extractions were performed using a CTAB protocol slightly modified from Doyle \& Doyle (1990). PCR amplification of nrITS (nuclear ribosomal internal transcribed spacer) and nrLSU (large subunit ribosomal DNA) was performed using the primer pairs ITS5/ITS4, ITS1F/ITS4, LR0R/LR5. Parts of the protein-coding genes $\beta$-tubulin and $r p b 2$ (second largest subunit of RNA polymerase II) were amplified using the primer pairs Am- $\beta$-tub-F/Am- $\beta$-tub-R and Am6F/Am-7R, respectively (Cai et al. 2014). Purified PCR products were then sequenced using the same primer combinations as for PCR at Macrogen Europe (Amsterdam) using an ABI 3730 XL DNA analyzer (Applied Biosystems). Forward and reverse reads were assembled and edited with Geneious Pro 5.1.7 (Biomatters Ltd., Auckland, New Zealand).

\section{DNA sequence dataset assembly}

Ninety-two sequences of collections were newly generated for this study and deposited in GenBank (GB) (http://www.ncbi.nlm.nih.gov/, Table 1). Initial BLAST searches (http://blast.ncbi.nlm.nih.gov) of both nrLSU and ITS1+5.8S+ITS2 sequences were performed to estimate similarity with Amanita sequences already in GB. Additional sequences to be included in the phylogenetic analyses were retrieved from GB (Table 1).

\section{Phylogenetic analyses}

Sequences were initially aligned with MAFFT v.7.0 (Katoh et al. 2005) using the G-INS-i iterative refinement algorithm, with minimal manual adjustment in BioEdit v.7.0.9 (Hall 1999). Introns of protein-coding genes were excluded from the analyses. For the nrITS region, the different loci of the region were identified on the basis of terminal motifs of $18 \mathrm{~S}, 5.8 \mathrm{~S}$ and $28 \mathrm{~S}$ loci catalogued (Rodríguez-Caycedo et al. 2018). Only the positions corresponding to ITS1, 5.8S, and ITS2 were kept in the alignment. The program Gblocks v0.91b (Castresana 2000) was then used to exclude poorly aligned positions of the nrITS alignment with the following parameter settings: minimum number of sequences for a conserved position $=12$; minimum number of sequences for a flank position $=14$; maximum number of contiguous non-conserved positions $=4 \mathrm{bp}$, minimum block size $=3 \mathrm{bp}$, and gaps allowed within selected blocks in half of the sequences. Phylogenetic tree inference was performed using both Maximum Likelihood (ML) and Bayesian Inference (BI). The ML analyses were performed using RAxML-HPC2 (Stamatakis 2014) on the CIPRES Science Gateway (Miller et al. 2009), with default settings except the number of bootstrap replicates was set to 1,000 for both single-gene and combined gene analyses. Phylogenetic inference was first performed on each single-gene alignment, and, since no significantly supported conflict (with ML bootstrap support $\geq 70 \%$ ) was detected, multiple-gene alignments and trees were built. Because nrITS sequences were not alignable with reasonable confidence over the whole set of OTUs include sect. Caesareae as outgroup. BI was performed using MrBayes v.3.2.6 (Ronquist et al. 2011), with a mixed model partition. The best substitution model was determined for each partition of the data set separately using MrModeltest v. 3.7 (Posada 2008) with default parameters. When the best model could not be specified in MrBayes, the next more complex model was used. The selected models were SYM+I for $\beta$-tubulin, SYM+G for $r p b 2, \mathrm{GTR}+\mathrm{I}+\mathrm{G}$ for ITS1, ITS2, and 5.8S. The Bayesian analyses were conducted with 2 runs, each with five simultaneous Markov chains, and trees were sampled every 250 generation. The analyses were stopped after 1,000,000 generations, when the average standard deviation of split frequencies was 0.003530 for the two-gene analysis, and 0.002856 for the four-gene analysis. The burn-in phase (20\% for the two-gene and four-gene analyses) was estimated by checking the stationarity in the plot generated by the sump and sumt commands. The remaining trees were used to generate a majority-rule consensus tree and to compute corresponding posterior probabilities. Phylograms were visualized with FigTree ver. 1.3.1 (Rambaut 2009). 
Table 1 Taxa of Amanita included in molecular analyses, with voucher specimen numbers, country of origin, and GenBank accession numbers.

\begin{tabular}{|c|c|c|c|c|c|c|}
\hline \multirow{2}{*}{ Species name } & \multirow{2}{*}{ Voucher } & \multirow{2}{*}{ Country } & \multicolumn{4}{|c|}{ GenBank accession no. } \\
\hline & & & nrITS & nrLSU & $r p b 2$ & $\beta$-tubulin \\
\hline \multicolumn{7}{|l|}{ sect. Vaginatae } \\
\hline A. brunneoprocera & BZ2015-24 & Thailand & MF461573 & MF461553 & MF440412 & MF440386 \\
\hline A. brunneosquamata & BZ2014-08 & Thailand & MF461582 & MF461566 & MF440410 & MF440384 \\
\hline A. brunneosquamata & BZ2015-73 & Thailand & MF461581 & MF461563 & MF440422 & MF440396 \\
\hline A. brunneoumbonata & BZ2015-67 & Thailand & MF461579 & MF461561 & MF440420 & MF440394 \\
\hline A. cinnamomea & BZ2015-45 & Thailand & - & MF461555 & MF440414 & MF440388 \\
\hline A. cinnamomea & BZ2015-48 & Thailand & MF461576 & MF461557 & MF440416 & MF440390 \\
\hline A. cinnamomea & BZ2015-49 & Thailand & MF461577 & MF461558 & MF440417 & MF440391 \\
\hline A. flammeola Pegler \& Piearce & JD960 & DR Congo & MF461585 & - & MF440424 & MF440398 \\
\hline A. flavidocerea & BZ2015-59 & Thailand & - & MF461559 & MF440418 & MF440392 \\
\hline A. flavidocerea & BZ2015-60 & Thailand & MF461578 & MF461560 & MF440419 & MF440393 \\
\hline A. flavidogrisea & BZ2015-44 & Thailand & MF461574 & MF461554 & MF440413 & MF440387 \\
\hline A. friabilis (P. Karst.) Bas & AF2529 & Belgium & - & - & MF440404 & MF440378 \\
\hline A. fulva Fr. & HDM9867 & Belgium & MF461586 & - & MF440423 & MF440397 \\
\hline A. luteoparva & BZ2015-46 & Thailand & MF461575 & MF461556 & MF440415 & MF440389 \\
\hline A. magnivolvata Aalto & AF2528 & Belgium & MF461570 & MF461551 & MF440403 & MF440377 \\
\hline A. malleata Piane & AM91-255 & Belgium & MF461572 & - & MF440406 & MF440380 \\
\hline A. olivaceogrisea Kalamees & AF2427 & The Netherlands & MF461569 & - & MF440402 & MF440376 \\
\hline A. simulans Contu & JM0303 & Belgium & MF461583 & - & MF440425 & MF440399 \\
\hline A. simulans & RLE/2013/1367 & Belgium & MF461568 & - & MF440427 & MF440400 \\
\hline A. submembranacea (Bon) Gröger & AF3130 & Belgium & MF461571 & MF461552 & MF440405 & MF440379 \\
\hline A. suborientifulva & OR1276 & Thailand & MF461584 & MF461567 & MF440426 & MF440401 \\
\hline A. suborientifulva & BZ2013-55 & Thailand & - & MF461564 & - & - \\
\hline
\end{tabular}


Table 1 Continued.

\begin{tabular}{|c|c|c|c|c|c|c|}
\hline \multirow{2}{*}{ Species name } & \multirow{2}{*}{ Voucher } & \multirow{2}{*}{ Country } & \multicolumn{4}{|c|}{ GenBank accession no. } \\
\hline & & & nrITS & nrLSU & $r p b 2$ & $\beta$-tubulin \\
\hline A. subovalispora & BZ2014-06 & Thailand & - & MF461565 & MF440409 & MF440383 \\
\hline A. subovalispora & BZ2015-70 & Thailand & MF461580 & MF461562 & MF440421 & MF440395 \\
\hline \multicolumn{7}{|l|}{ Outgroup (sect. Caesareae) } \\
\hline A. esculenta Hongo \& I. Matsuda & BZ2012-48 & Thailand & MF461587 & - & MF440407 & MF440381 \\
\hline A. hemibapha s.l. & BZ2014-22 & Thailand & MF461589 & - & MF440411 & MF440385 \\
\hline A. cf. princeps Corner \& Bas & BZ2013-102 & Thailand & MF461588 & - & MF440408 & MF440382 \\
\hline
\end{tabular}

\section{Results}

\section{Phylogenetic analysis}

In this study, each of the single-gene phylogenies showed similar tree topologies (not shown). The two-gene ( $\beta$-tubulin and $r p b 2)$ and four-gene ( $\beta$-tubulin, $r p b 2$, ITS1+ITS2, and 5.8S) alignments contained 26 OTUs, and were 967 and 1,413 sites long, respectively. For the ITS1 + ITS2 alignment, Gblocks retained 446 sites (67\% of a total of 663 sites). The phylogenetic analyses produced several unique clades of Thai collections that remained separate from taxa reported from Europe and USA, but often with weak support. I) Amanita brunneoumbonata formed a sister taxa to A. magnivolvata (BS $=100 \%$ ). II) Amanita cinnamomea and A. brunneosquamata are sister taxa clustered into a single clade with BS $=70 \%$ in four-gene tree and 66\% in two-gene tree. III) Amanita flavidocerea and A. brunneoprocera were sister taxa in another single clade in the four-gene tree but did not cluster close together in the two-gene tree; branch support was weak in both trees. IV) A clade with only A. subovalispora indicated that it did not form a close relationship with any other species in the four-gene tree with BS $=89 \%$ and in the two-gene tree it clustered with several other taxa from Thailand, as well as A. flammeola from Europe, but there was poor support for this topology with BS=50\%. V) Amanita flavidogrisea and A. luteoparva clustered together in a single clade in the four-gene tree with relatively poor support, and each formed its own single taxon clade in the two-gene tree, but was likewise poorly supported. VI) A. suborientifulva formed a sister taxa with $A$. fulva with BS $=100 \%$, BS $=98 \%$ in the two-gene and four-gene trees, respectively. Initial BLAST searches of both nrL nrLSU and ITS1+5.8S+ITS2 sequences are given in Tables 2, 3. In this study, tree topologies obtained from ML and BI trees are shown in Figs. 1, 2. The aligned combined for the two-gene and four-gene dataset has been deposited in TreeBASE (TB2:S21478 and TB2:S21478, respectively). 


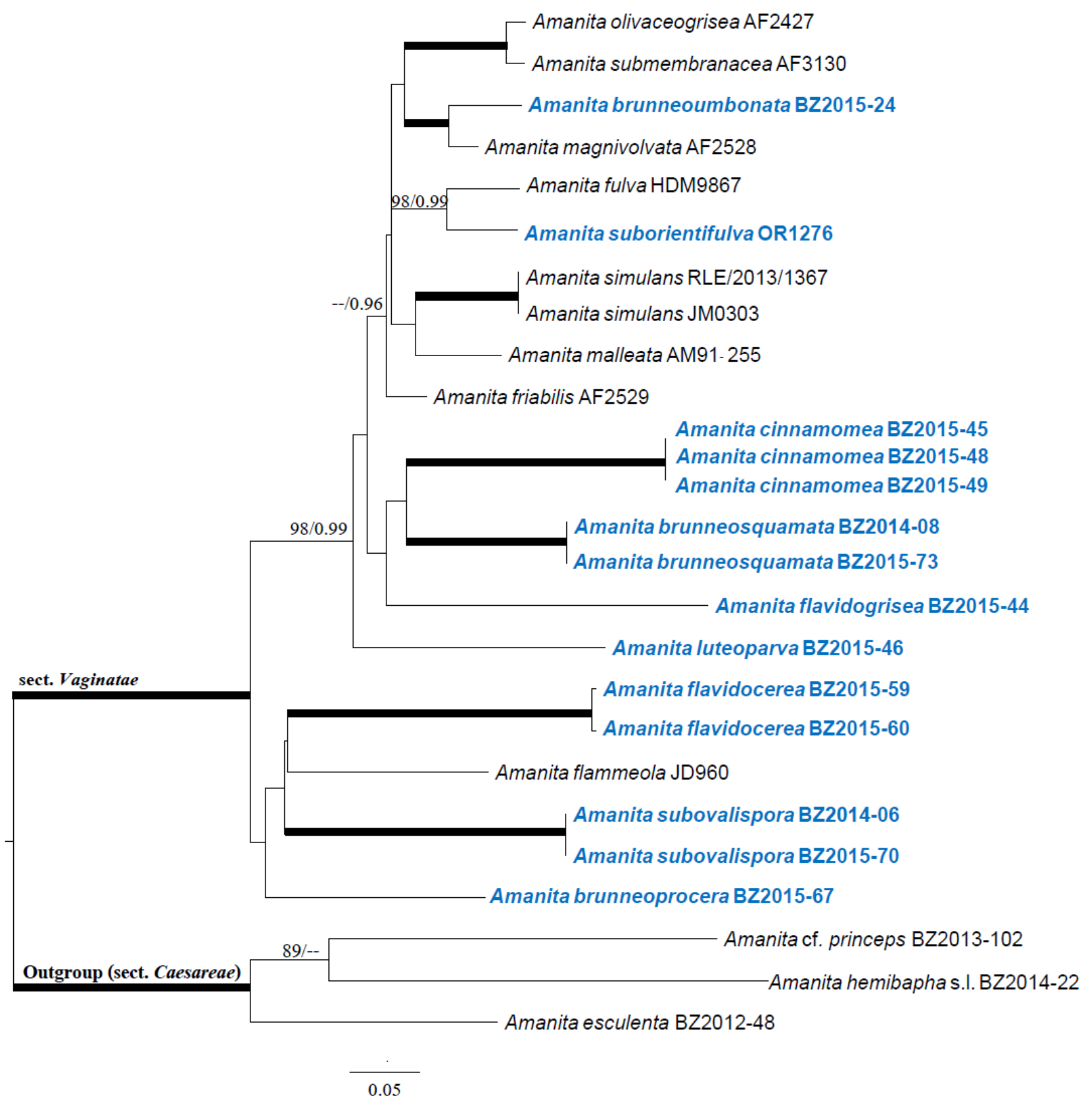

Figure 1 - Phylogenetic tree inferred from two-gene combined dataset ( $\beta$-tubulin and $r p b 2)$ using Maximum Likelihood (ML). Bootstrap values (BS) $\geq 70 \%$ and corresponding Posterior Probabilities $(\mathrm{PP}) \geq 0.95$ are shown above the branches, except when $\mathrm{BS}=100 \%$ and $\mathrm{PP}=1.0$, which are indicated as thick branches. Amanita in sect. Vaginatae were collected from Thailand are highlighted in blue. Voucher collection identifiers are provided after each species name. 


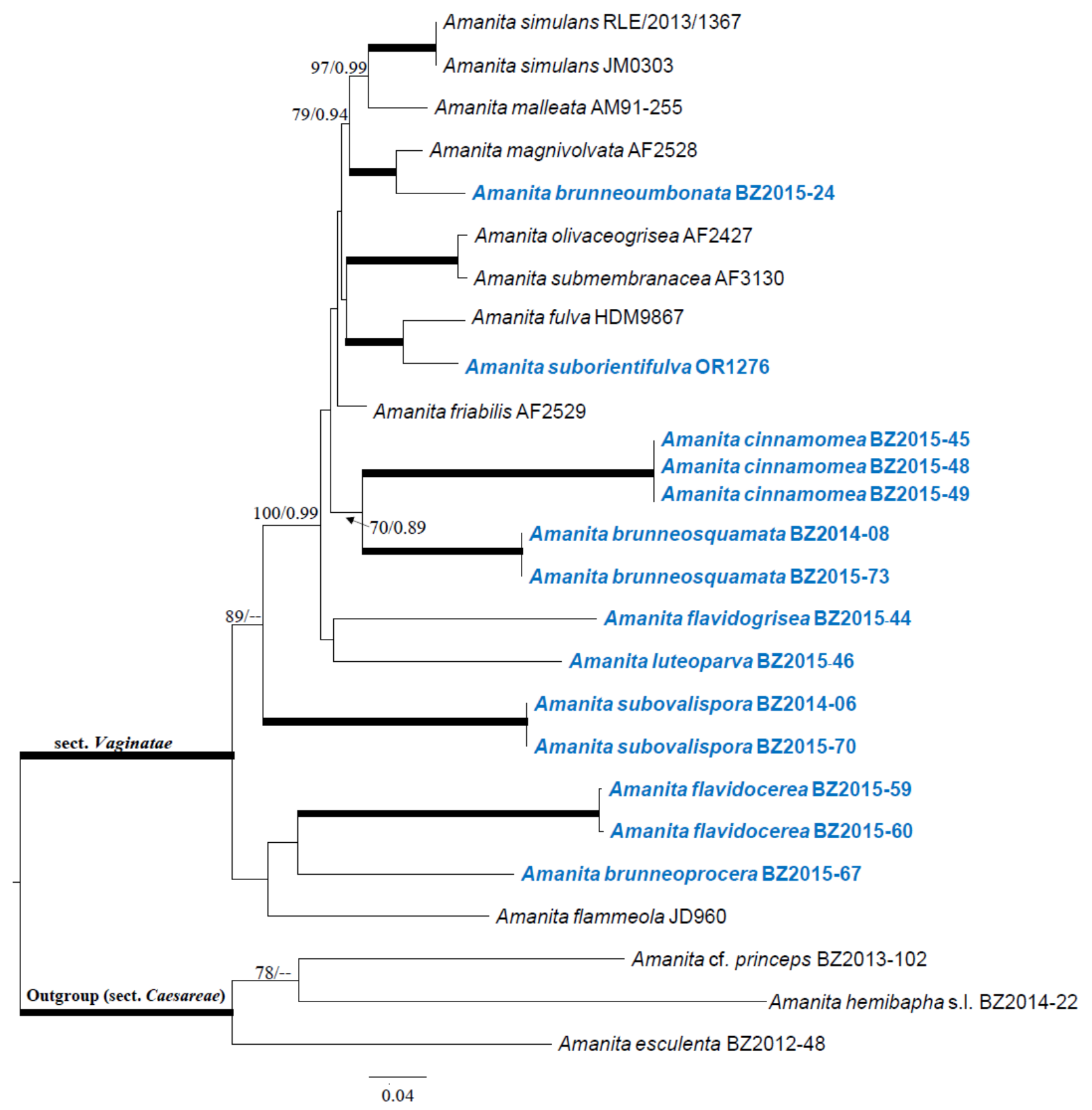

Figure 2 - Phylogenetic tree inferred from four-gene combined dataset ( $\beta$-tubulin, rpb2, ITS1+ITS2, and 5.8S) using Maximum Likelihood (ML). Bootstrap values (BS) $\geq 70 \%$ and corresponding Posterior Probabilities $(\mathrm{PP}) \geq 0.95$ are shown above the branches, except when $\mathrm{BS}=$ $100 \%$ and $\mathrm{PP}=1.0$, which are indicated as thick branches. Amanita in sect. Vaginatae were collected from Thailand are highlighted in blue. Voucher collection identifiers are provided after each species name. 
Table 2 Results of GenBank BLAST searches for nrITS sequences of Amanita species collected from Thailand (S = Similarity and $\mathrm{QC}=$ Query Cover).

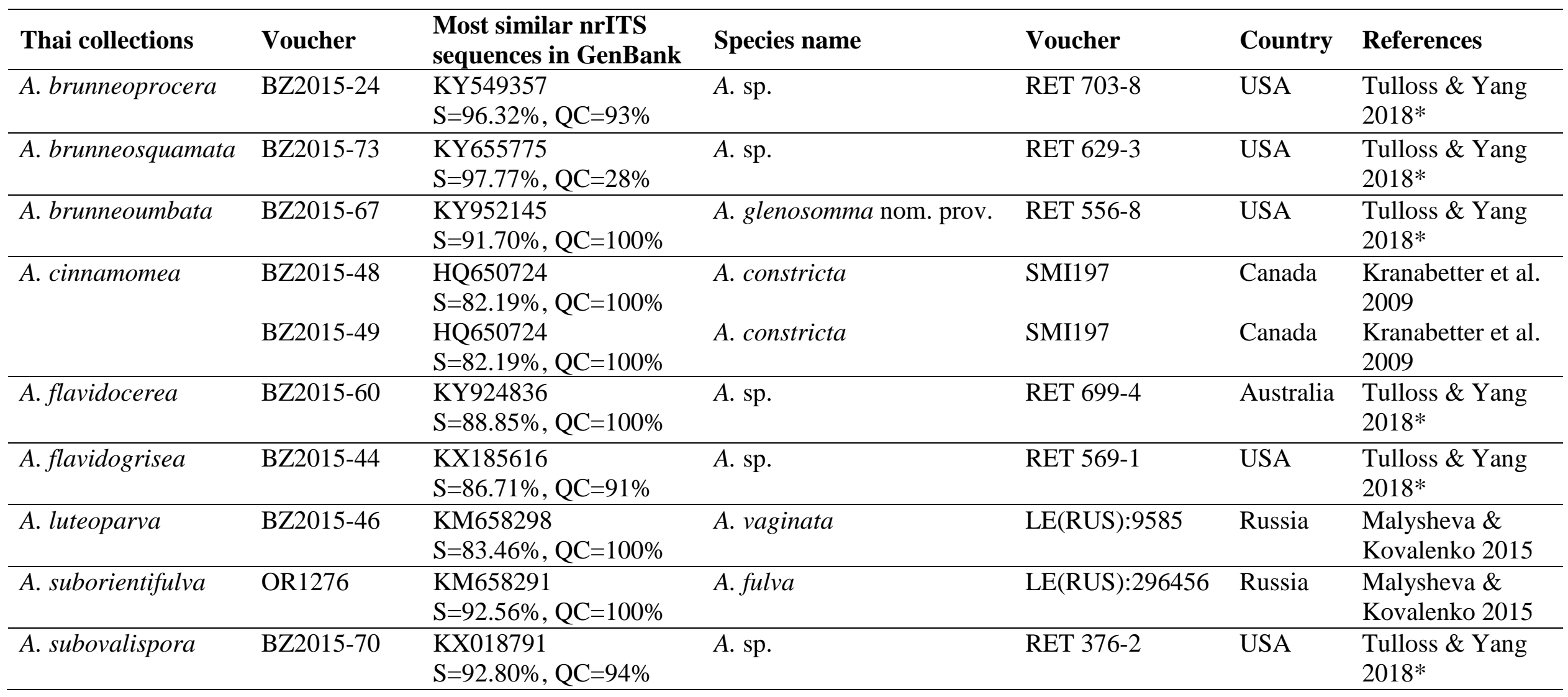


Table 3 Results of GenBank BLAST searches for nrLSU sequences of Amanita species collected from Thailand ( $=$ =Similarity and QC $=$ Query Cover).

\begin{tabular}{|c|c|c|c|c|c|c|}
\hline Thai collections & Voucher & $\begin{array}{l}\text { Most similar nrLSU } \\
\text { sequences in GenBank }\end{array}$ & Species name & Voucher & Country & References \\
\hline A. brunneoprocera & BZ2015-24 & $\begin{array}{l}\text { KY549344 } \\
S=97.19 \%, Q C=100 \%\end{array}$ & A. sp. & RET 703-8 & USA & $\begin{array}{l}\text { Tulloss \& Yang } \\
\text { 2018* }\end{array}$ \\
\hline A. brunneosquamata & $\begin{array}{l}\text { BZ2014-08 } \\
\text { BZ2015-73 }\end{array}$ & $\begin{array}{l}\text { KU248121 } \\
\mathrm{S}=95.26 \%, \mathrm{QC}=100 \% \\
\mathrm{KU} 248121 \\
\mathrm{~S}=95.26 \%, \mathrm{QC}=100 \%\end{array}$ & $\begin{array}{l}\text { A. friabilis } \\
\text { A. friabilis }\end{array}$ & RET 396-1 & France & $\begin{array}{l}\text { Tulloss \& Yang } \\
\text { 2018* } \\
\text { Tulloss \& Yang } \\
\text { 2018* }\end{array}$ \\
\hline A. brunneoumbonata & BZ2015-67 & $\begin{array}{l}\text { KY952146 } \\
S=99.68 \%, Q C=100 \%\end{array}$ & A. glenosomma nom. prov. & RET 556-8 & USA & $\begin{array}{l}\text { Tulloss \& Yang } \\
\text { 2018* }\end{array}$ \\
\hline A. cinnamomea & $\begin{array}{l}\text { BZ2015-45 } \\
\text { BZ2015-49 }\end{array}$ & $\begin{array}{l}\text { KY614227 } \\
S=96.03 \%, Q C=100 \% \\
K Y 614227 \\
S=96.24 \%, Q C=100 \%\end{array}$ & $\begin{array}{l}\text { A. } \mathrm{sp} \text {. } \\
\text { A. sp. }\end{array}$ & $\begin{array}{l}\text { RET 690-10 } \\
\text { RET 690-10 }\end{array}$ & $\begin{array}{l}\text { USA } \\
\text { USA }\end{array}$ & $\begin{array}{l}\text { Tulloss \& Yang } \\
\text { 2018* } \\
\text { Tulloss \& Yang } \\
\text { 2018* }\end{array}$ \\
\hline A. flavidocerea & $\begin{array}{l}\text { BZ2015-59 } \\
\text { BZ2015-60 }\end{array}$ & $\begin{array}{l}\text { KY435389 } \\
S=97.58 \%, Q C=100 \% \\
K Y 435389 \\
S=97.58 \%, Q C=100 \%\end{array}$ & $\begin{array}{l}\text { A. sp. } \\
\text { A. sp. }\end{array}$ & $\begin{array}{l}\text { RET 603-5 } \\
\text { RET 603-5 }\end{array}$ & $\begin{array}{l}\text { Australia } \\
\text { Australia }\end{array}$ & $\begin{array}{l}\text { Tulloss \& Yang } \\
\text { 2018* } \\
\text { Tulloss \& Yang } \\
\text { 2018* }\end{array}$ \\
\hline A. flavidogrisea & BZ2015-44 & $\begin{array}{l}\text { KU248121 } \\
S=96.03 \%, Q C=100\end{array}$ & A. friabilis & RET 396-1 & France & $\begin{array}{l}\text { Tulloss \& Yang } \\
\text { 2018* }\end{array}$ \\
\hline A. luteoparva & BZ2015-46 & $\begin{array}{l}\text { KP866162 } \\
S=96.55 \%, Q C=100 \%\end{array}$ & A. sp. & RET 371-3 & Canada & $\begin{array}{l}\text { Tulloss \& Yang } \\
\text { 2018* }\end{array}$ \\
\hline A. suborientifulva & OR1276 & $\begin{array}{l}\text { KP866162 } \\
S=97.69 \%, Q C=100 \%\end{array}$ & A. daimonioctantes nom. prov. & RET 371-3 & Canada & $\begin{array}{l}\text { Tulloss \& Yang } \\
\text { 2018* }\end{array}$ \\
\hline A. subovalispora & $\begin{array}{l}\text { BZ2014-06 } \\
\text { BZ2015-70 }\end{array}$ & $\begin{array}{l}\text { KX018801 } \\
S=96.33 \%, Q C=96 \% \\
K X 018802 \\
S=97.09 \%, Q C=96 \%\end{array}$ & $\begin{array}{l}\text { A. sp. } \\
\text { A. sp. }\end{array}$ & $\begin{array}{l}\text { RET 376-2 } \\
\text { RET 375-9 }\end{array}$ & $\begin{array}{l}\text { USA } \\
\text { USA }\end{array}$ & $\begin{array}{l}\text { Tulloss \& Yang } \\
\text { 2018* } \\
\text { Tulloss \& Yang } \\
\text { 2018* }\end{array}$ \\
\hline
\end{tabular}

\footnotetext{
${ }^{*}$ www.amanitaceae.org
} 


\section{Taxonomy}

Amanita brunneoprocera Thongbai \& Raspé \& K.D. Hyde, sp. nov.

Fig. 3

MycoBank number MB821501; Facesoffungi number: FoF03375.

Type - Thailand: Chiang Rai Province: Doi Pui, Meuang District, ThaSai Subdistrict, Reverse Signal Station, elev. 730 m, N1948'57" E 9952'0", 05 Aug. 2015, B. Thongbai BZ201524 (MFLU 15-3322 - holotype; BBH 42257 - isotype).

Etymology - "brunneoprocera" refers to the dark brown color of the pileus and long stipe.

Basidiomata medium-sized. Pileus $65-80 \mathrm{~mm}$ in diameter, convex to plane at maturity, subumbonate to umbonate, dull, dry, slightly viscid when moist, glabrous, minutely fibrillose, brownish beige, greyish brown to dark brown toward margin (6D3-4, 6E4-5, 7F5-6), darker at center, paler towards margin; mostly lacking universal veil remnants; margin incurved to flaring upward, striate-tuberculate $(0.18-0.21 \mathrm{R})$, non-appendiculate; context $2-5 \mathrm{~mm}$ thick above stipe, soft, white to whitish (1A1), unchanging. Lamellae 4-6 mm wide, free, crowded, pale yellow to cream (3A3) in aspect and white to pale yellow (2A2) in side view, marginate, with lamellar edge white to whitish (1A1), minutely eroded; lamellulae of 3-6 lengths, sub-truncate to truncate. Stipe 130-210 × 6-14 mm, subcylindrical, slightly tapering upwards and flaring at very apex, white to yellowish white background (3A1-2), covered with fibrillose squamules on upper and lower part, paler orange grey to brownish grey $(5 \mathrm{~B} 2-6 \mathrm{C} 2)$, becoming darker in bands in central part, unchanging when bruised; context hollow or partially stuffed, soft, white to yellowish white (3A12), unchanging when cut. Bulb absent. Universal veil on stipe base saccate volva, 36-45 $\mathrm{mm}$ from base of stipe to highest point of limb, membranous, thin, closed tightly around stipe, moderately tough; outer surface white (1A1), inner surface yellowish white (3A2). Partial veil absent. Spore print white. Odor and taste not recorded.

Lamellar trama bilateral, divergent; mediostratum 60-80 $\mu$ m wide; filamentous hyphae 2-8 $\mu \mathrm{m}$ wide, branching, hyaline, with slightly inflated elements; no vascular hyphae observed. Subhymenium 30-45 $\mu \mathrm{m}$ thick in 2-3 layers, with subglobose to ovoid cells dominating, 9-15 $\times 8-$ $11 \mu \mathrm{m}$, subtended by concatenated partially inflated hyphal segments. Basidia 50-65 × 12-19 $\mu \mathrm{m}$, narrowly clavate to clavate, mostly 4-, occasionally 2 -spored, with sterigmata up to $5 \mu \mathrm{m}$ long; no clamps observed at base of basidia. Basidiospores [150/3/1] (8.5-) 8.5-9.8 (-10.5) $\times(8.0-)$ 8.1-9.2 $(-9.5) \mu \mathrm{m},\left(\mathrm{L}^{\prime}=9.25 \mu \mathrm{m} ; \mathrm{W}^{\prime}=8.74 \mu \mathrm{m} ; \mathrm{Q}=1.0-1.15(-1.16) ; \mathrm{Q}^{\prime}=1.06 \pm 0.05\right)$, smooth, hyaline, colorless, thin-walled, inamyloid, globose to subglobose, rarely broadly ellipsoid, occasionally adaxially flattened; apiculus rather variable, sublateral, small, up to $2 \mu \mathrm{m}$ long, cylindric to truncate-conic; contents monoguttulate or occasionally granular. Lamellar edge sterile; filamentous hyphae 3-7 $\mu \mathrm{m}$ wide, hyaline, colorless or pale yellow, thin-walled; mostly globose to subglobose and sometimes ovoid, 20-25 × 18-22 $\mu \mathrm{m}$, colorless, thin-walled. Pileipellis up to 90-110 $\mu \mathrm{m}$ thick, made of two layers; suprapellis $40-50 \mu \mathrm{m}$ thick, slightly gelatinized with filamentous undifferentiated hyphae 3-5 $\mu \mathrm{m}$ wide, branching, interwoven, colorless, thin walled; subpellis 50$60 \mu \mathrm{m}$ thick, not gelatinized, with filamentous undifferentiated hyphae 2-5 $\mu \mathrm{m}$ wide, branching, with intracellular pale brownish-white pigments, thin-walled; vascular hyphae 4-6 $\mu \mathrm{m}$ wide, flexuose, branching, coiling, common to frequent, scattered; no clamps observed. Pileus context filamentous hyphae 3-5 $\mu \mathrm{m}$ wide, frequently branching mixed with abundant inflated cells, with terminal broadly clavate to clavate cells, sometimes broadly globose 50-60 × 70-90 $\mu \mathrm{m}$, thinwalled and vascular hyphae 6-10 $\mu \mathrm{m}$ wide, sinuous, rare, scattered; no clamps observed. Universal veil on stipe base exterior surface gelatinized, with filamentous hyphae $6-16 \mu \mathrm{m}$ wide; inflated cells, with terminal ovoid to broadly clavate $60-75 \times 55-73 \mu \mathrm{m}$ cells; vascular hyphae 6-10 $\mu \mathrm{m}$ wide, sinuous, frequent, scattered; interior surface similar to exterior surface, with abundant filamentous hyphae 5-15 $\mu \mathrm{m}$ wide; inflated cells, with terminal ovoid to broadly clavate 58-73 $\times$ 45-62 $\mu \mathrm{m}$ cells; vascular hyphae 8-10 $\mu \mathrm{m}$ wide, sinuous, scattered; no clamps observed. Stipe trama longitudinally acrophysalidic; filamentous hyphae undifferentiated $2.5-9 \mu \mathrm{m}$ wide, thinwalled, frequently branching; acrophysalides up to $250-430 \times 26-38 \mu \mathrm{m}$, thin-walled; vascular hyphae 5-12.5 $\mu \mathrm{m}$ wide, sinuous, rare, scattered; no clamps observed. 
Habitat - Scattered on the ground in Fagaceae or mixed Dipterocarpaceae-Fagaceae forest. Distribution - Currently only known from northern Thailand.
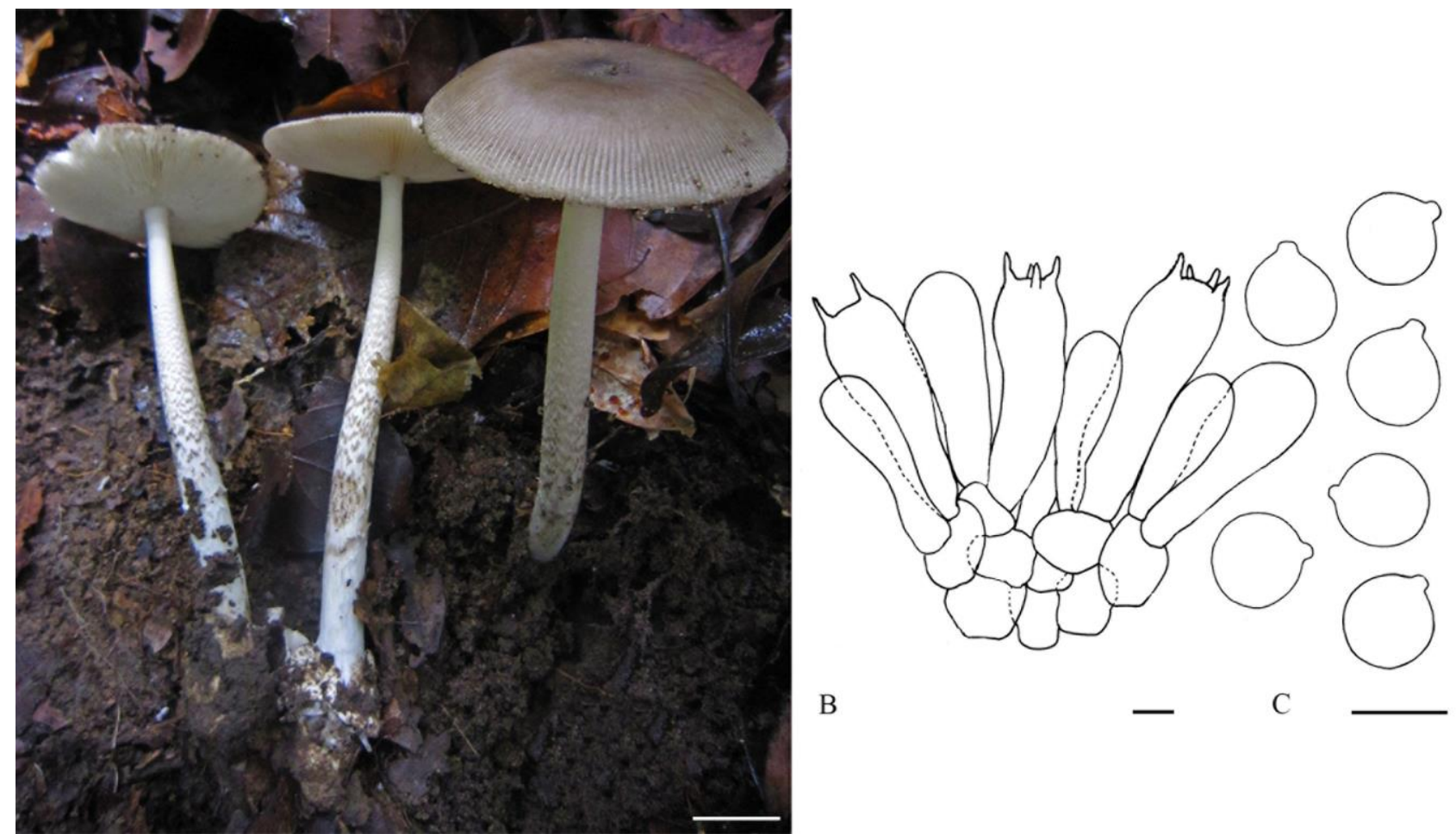

Figure 3 - Amanita brunneoprocera (BZ2015-24). A Basidiomata. B Hymenium and subhymenium. C Basidiospores. Scale bars: $A=2 \mathrm{~cm}$;,$C=10 \mu \mathrm{m}$.

Remarks - Amanita brunneoprocera was collected Fagaceae or mixed DipterocarpaceaeFagaceae, scattered on wet to sandy soils. Amanita brunneoprocera is characterized by its subumbonate to umbonate pileus that is greyish brown to dark brown toward margin and has a minutely fibrillose surface. The stipe is covered with fibrillose squamules, brownish grey on upper part, paler on lower part, but darker in bands mostly in central part. Among species that have a dark brown sub-umbonate to umbonate pileus and stipe decorated with gray fibrillose squamules, $A$. brunneoprocera is similar to A. atrofusca Zhu L. Yang, A. fuligineodisca Tulloss, Ovrebo \& Halling, A. humboldtii Singer, A. pekeoides G. S. Ridl, A. tomentosivolva Zhu L. Yang, and A. umbrinolutea (Secr. ex Gillet) Bataille. However, A. atrofusca, found in the subalpine to alpine regions of southwestern China, differs from A. brunneoprocera in having a stipe that is densely covered with dark brown squamules, and the outer portion of the saccate volva is covered with brownish spots. The globose to subglobose basidiospores $\left(\mathrm{Q}^{\prime}=1.04\right)$ of $A$. atrofusca are larger [(9.5-) 11.0-14.5 (-15.0) × (8.5-) 11.0-14.5 (-15.0) $\mu \mathrm{m}$; (Yang 1997)], than those, subglobose to broadly ellipsoid of A. brunneoprocera [(8.5-) 8.5-9.8 (-10.5) $\times(8.0-)$ 8.1-9.2 (-9.5)], and the marginal striations on the pileus are slightly longer $(0.2-0.3 \mathrm{R})$. The macroscopical descriptions of A. humboldtii and A. fuligineodisca are similar to A brunneoprocera; however, both species can be differentiated from $A$ brunneoprocera by having a saccate volva that is largely free from the stipe and ranging in color from white to cinnamon or orange, while A. brunneoprocera has a white to yellowish white saccate volva that is closed tightly around stipe. Amanita humboldtii was first found in Colombia associated with oak trees, and seems to be a rare species (Singer 1963). Amanita pekeoides is naturally associated with Nothofagus and Leptospermum, and is currently only known from New Zealand. In the field, A. pekeoides can be differentiated from A. brunneoprocera by the stipe that is densely decorated, from the apex to the base, with a grayish sepia banded pattern and a buff-colored saccate volva, with ochraceous to fulvous stains. Amanita tomentosivolva, from subtropical to tropical areas in China, has a saccate volva with outer surface decorated with rust- 
brown, floccose, irregularly formed patches. It also has slightly longer marginal striations on the pileus $(0.3 \mathrm{R})$, and relatively larger, globose to subglobose basidiospores [(11.0-) 11.5-14.0 $\times$ (10.5-) 11.0-13.5 $\mu \mathrm{m} ; \mathrm{Q}^{\prime}=1.04$ ] (Yang 1997), than A. brunneoprocera with marginal striations on the pileus $0.18-0.21 \mathrm{R}$, spores (8.5-) 8.5-9.8 (-10.5) $\times(8.0-)$ 8.1-9.2 (-9.5) and $\mathrm{Q}^{\prime}=1.06$. Amanita umbrinolutea is associated with coniferous trees. It has a distinctly umbonate pileus with color at the center that abruptly contrasts with a paler margin, while the coloration of the pileus in A. brunneoprocera does not exhibit the abruptly contrasting colors. In addition, A. umbrinolutea has slightly larger basidiospores [(9.5-) 10.5-13.4 (-17.2) × (8.5-) 9.5-12.5 (-14.8) $\mu \mathrm{m}$ (Bataille 1910); $\left.\mathrm{Q}^{\prime}=1.08\right]$, and longer striations (0.2-0.4 R).

Amanita brunneosquamata Thongbai, Raspé \& K.D. Hyde, sp. nov.

Fig. 4 MycoBank number MB821503; Facesoffungi number FoF03376.

Type - Thailand: Prov. Chiang Mai Province: Mae On District, Huay Kaeo, elev. 1030 m, N18 53.08" E99 21.45", 18 Aug. 2015, B. Thongbai BZ2015-73 (MFLU 15-3369 - holotype; BBH 42256 - isotype).

Additional specimen examined - Thailand: Prov. Chiang Mai: Doi Saket District, Thep Sadet Subdistrict, elev. 1300 m, N1855'39" E99 21'59", 30 June 2014, B. Thongbai BZ2014-08 (MFLU 15-0097, BBH 42255).

Etymology - "brunneosquamata" refers to the brownish color of the pileus and the banded pattern of squamules on the stipe.

Basidiomata medium-sized to large. Pileus $90-100 \mathrm{~mm}$ in diameter, parabolic to hemispheric when young, convex to plane at maturity, often shallowly depressed at center, dry, shiny, viscid when moist, glabrous, light greyish to greyish brown (5C2-3), slightly darker at center, becoming light grey towards margin (5B1); with universal veil remnants present or absent, if present as a smooth, single large patch when young, greyish white (5A1 or lighter than $5 \mathrm{~A} 2$ ), often absent at maturity; margin incurved to flaring upward, Finely striate when young to sulcate when mature (0.44-0.46 R), non-appendiculate; context 5-8 mm thick above stipe, soft, pale yellowish or white (1A1), unchanging. Lamellae 4-6 mm wide, free, crowded, yellowish white (3A2-3) in aspect and yellowish white or milk white (lighter than 2A2)in side view, marginate, with lamellar edge grey (5B1), minutely eroded; lamellulae of 3-6 lengths, attenuate to nearly truncate. Stipe 150-168 $\times 8-$ $17 \mathrm{~mm}$, cylindrical or slightly tapering upwards, with short decurrent line at apex, light brownish orange to brownish grey (6C2-3) background, often covered with a layer of paler brownish grey fine flocculae or squamules that separates into bands on apex, giving the appearance of darker squamules in bands; unchanging when bruised; context hollow or partially stuffed, soft, yellowish white (4A2), unchanging when cut. Bulb absent. Universal veil on stipe base saccate volva, 25-38 $\mathrm{mm}$ from base of stipe to highest point of limb, membranous, 2-3 $\mathrm{mm}$ thick, flimsy, fragile, easily breakable or often forming incomplete belt; outer surface white (1A1), inner surface slightly greyish white (1B2). Partial veil absent. Spore print white. Odor and taste not recorded.

Lamellar trama bilateral, divergent; mediostratum 30-40 $\mu \mathrm{m}$ wide; filamentous hyphae 2.8$6.2 \mu \mathrm{m}$ wide, branching, hyaline, with slightly inflated elements; vascular hyphae 2.6-6 $\mu \mathrm{m}$ wide, flexuose, scattered; no clamps observed. Subhymenium 38-64 $\mu \mathrm{m}$ thick in 3-4 layers, with broadly clavate or ovoid cells dominating, 9-16 $\times 7-11 \mu \mathrm{m}$, also with broadly cylindrical cells, some with slight median constriction, subtended by concatenated partially inflated hyphal segments. Basidia 58-65 × 14-19 $\mu \mathrm{m}$, narrowly clavate to clavate, mostly 4-, occasionally 2-spored, with sterigmata up to $5 \mu \mathrm{m}$ long; no clamps observed at base of basidia. Basidiospores [100/2/2] (7.9-) 8-9.6 ($10.7) \times(7.6-) 7.7-9.2(-9.9) \mu \mathrm{m},\left(\mathbf{L}^{\prime}=8.8 \mu \mathrm{m} ; \mathbf{W}^{\prime}=8.4 \mu \mathrm{m} ; \mathbf{Q}=(1.00-) 1.01-1.12(1.14) ; \mathbf{Q}^{\prime}=\right.$ $1.05 \pm 0.04)$, smooth, hyaline, colorless, thin-walled, inamyloid, globose to subglobose; apiculus rather variable, sublateral, rather small, up to $1.5 \mu \mathrm{m}$ long, truncate-cylindric to rarely truncateconic; contents monoguttulate. Lamellar edge sterile; filamentous hyphae 3-7 $\mu \mathrm{m}$ wide, hyaline, colorless or pale yellow, thin-walled; mostly globose to subglobose dominating, and sometimes ovoid, 11-15 × 9-14 $\mu \mathrm{m}$, colorless, thin-walled. Pileipellis up to 150-280 $\mu \mathrm{m}$ thick, made of two layers; suprapellis 70-85 $\mu \mathrm{m}$ thick, gelatinized, with filamentous undifferentiated hyphae 3-5 $\mu \mathrm{m}$ 
wide, interwoven, colorless, thin-walled; subpellis 80-195 $\mu \mathrm{m}$ thick, not gelatinized, with filamentous undifferentiated hyphae $2-5 \mu \mathrm{m}$ wide, branching, with intracellular yellowish-brown pigments, thin-walled; vascular hyphae 4-10 $\mu \mathrm{m}$ wide, flexuose, branching, coiling, common to frequent; no clamps observed. Pileus context filamentous hyphae 3-5 $\mu \mathrm{m}$ wide, frequently branching; inflated cells, with terminal broadly clavate to clavate 40-60 × 95-104 $\mu \mathrm{m}$ cells, thinwalled; vascular hyphae 8-12 $\mu \mathrm{m}$ wide, sinuous, rare, scattered; no clamps observed. Universal veil on stipe base exterior surface gelatinized, with filamentous hyphae 8-10 $\mu \mathrm{m}$ wide, interwoven; hyphae 3-5 $\mu \mathrm{m}$ wide, sinuous, rare, scattered; interior surface with abundant filamentous hyphae 5$10 \mu \mathrm{m}$ wide; inflated cells, with terminal globose to subglobose $26-35 \times 22-32 \mu \mathrm{m}$ cells; vascular hyphae 8-9 $\mu \mathrm{m}$ wide, sinuous, scattered; no clamps observed. Stipe trama longitudinally acrophysalidic; filamentous hyphae undifferentiated 2.3-8.4 $\mu \mathrm{m}$ wide, thin-walled, frequently branching; acrophysalides up to 62-222 × 10-21 $\mu \mathrm{m}$, thin-walled; vascular hyphae 2.5-7 $\mu \mathrm{m}$ wide, sinuous, rare, scattered; no clamps observed.
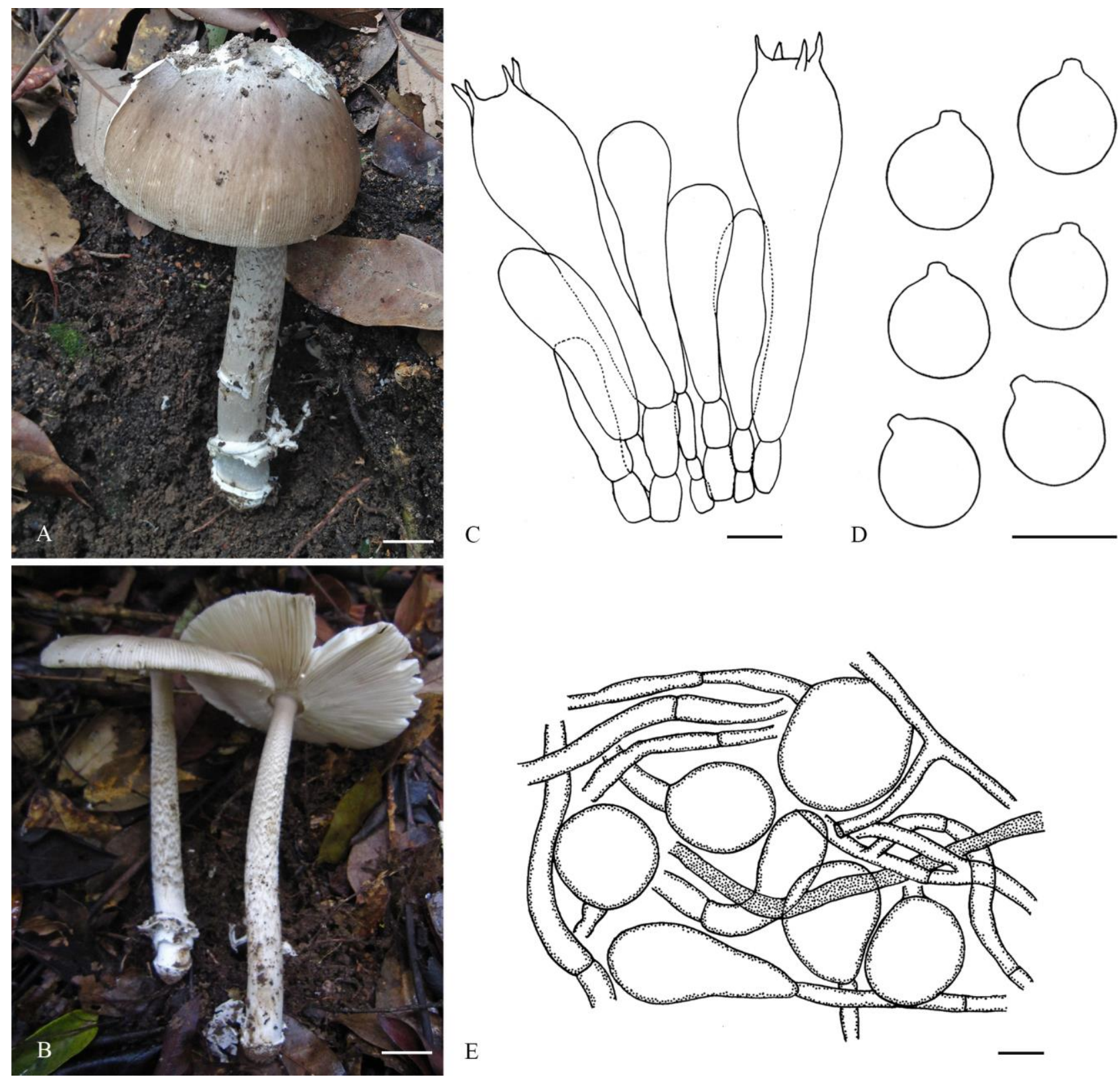

$\mathrm{E}$

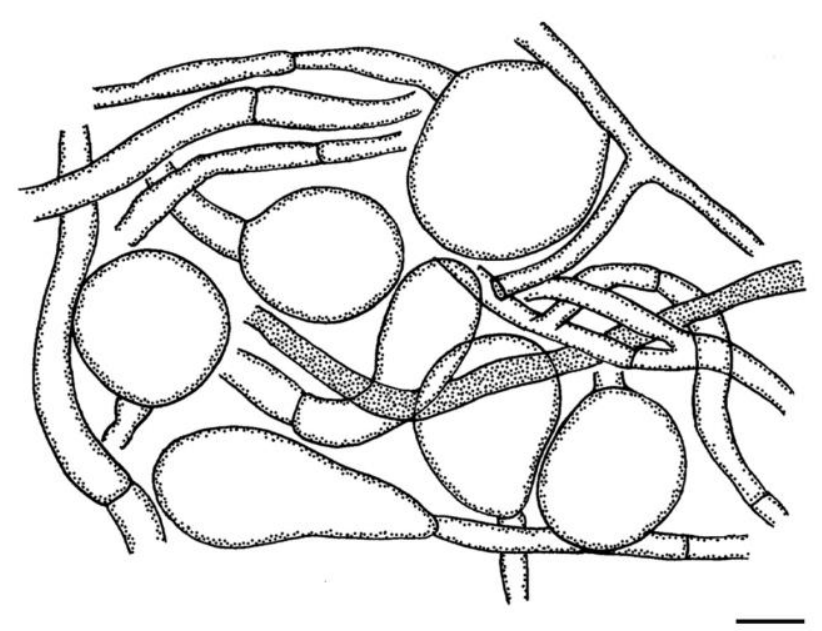

Figure 4 - Amanita brunneosquamata (BZ2015-73). A-B Basidiomata. C Hymenium and subhymenium. D Basidiospores. E Section of velar remnants from pileus. Scale bars: $\mathrm{A}-\mathrm{B}=2 \mathrm{~cm}$; $\mathrm{C}-\mathrm{E}=10 \mu \mathrm{m}$. 
Habitat - Scattered or solitary on the ground in Fagaceae forest.

Distribution - Currently only known from northern Thailand.

Remarks - Amanita brunneosquamata is characterized by a greyish brown pileus that is slightly darker at center, becoming light grey towards margin, with universal veil remnants as a smooth, single large greyish white patch present mostly in young basidiocarps. The stipe is covered with a layer of pale brownish grey fine flocculae or squamules that separate into bands near the apex allowing the darker background color to show, giving the appearance of distinctive darker bands. Amanita brunneosquamata has an uncomplete saccate volva that often forms an incomplete belt, a characteristic that is not common. However, there are other species with this characteristic, i.e. A. griseofolia Zhu L. Yang and A. liquii Zhu L. Yang, M. Weiss \& Oberw., both originally described from China, as well as A. madagascariensis L.P. Tang, Zhu L. Yang \& B. Buyck originally described from Madagascar. Although the general colors of the pileus and universal veil remnants are greyish to dark brownish in all these species, the characteristics of the stipe base of the three species differ from A. brunneosquamata. A. griseofolia, A. liquii, and $A$. madagascariensis all have grey to dark grey granular warts on an incomplete belt on the stipe base (Tang et al. 2015), while A. brunneosquamata has only pale brownish to grey fine flocculae or squamules and lacks warts on the stipe base. Amanita brunneosquamata and A. griseofolia both have globose to subglobose spores with similar $\mathbf{Q}^{\prime}(1.05$ and 1.04, respectively), but spores of $A$. brunneosquamata are smaller [(7.9-) 8-9.6 (-10.7) $\times(7.6-)$ 7.6-9.2 (-9.9)] than those of $A$. griseofolia [(9.5-) 10.0-13.5 (-16.5) $\times(8.5-)$ 9.5-13.0 (-15.0); Yang (2004)]. Moreover, the marginal striations are longer in A. brunneosquamata than in A. griseofolia $(0.44-0.46 \mathrm{R}$ and $0.2-$ $0.5 \mathrm{R}$, respectively). Amanita liquii has the same $\mathbf{Q}^{\prime}$ (1.05) but the spores are larger [(11.0-) 11.5$15.0(-24.0) \times(9.5-)$ 11.0-14.5 $(-20.0) \mu \mathrm{m}]$ and striations are shorter [(0.1-0.3 R); (Yang et al. 2004)]. A. madagascariensis has ellipsoid to elongate, larger spores $\left[\mathbf{Q}^{\prime}=1.69 ; 11-14(-15) \times(5-)\right.$ 6-8 (-9) $\mu \mathrm{m}$ ], and shorter striations [(ca. 0.1 R); (Tang et al. 2015)].

Amanita brunneoumbonata Thongbai, Raspé \& K.D. Hyde, sp. nov.

Fig. 5

MycoBank number MB821504; Facesoffungi number FoF03377.

Type - Thailand: Prov. Chiang Mai: Mae On District, Huay Kaeo, elev. 1052 m, N18 $53^{\prime} 6^{\prime \prime}$ E99'21'28", 18 Aug. 2015, B. Thongbai BZ2015-67 (MFLU 15-3363 - holotype; BBH 42254 isotype).

Etymology - "brunneoumbonata" refers to brown color and umbonate shape of pileus

Basidiomata medium-sized to large. Pileus $90-120 \mathrm{~mm}$ in diameter, parabolic to hemispheric when young, broadly convex to convex, then plane at maturity, often umbonate, dry, dull, slightly viscid when moist, virgate or dark radially fibrillose from center to margin, glabrous, brownish black to dark brown (9F5-8), light brown to brownish orange (7D6-8,7E6-7-8), dark central disc exceptionally large, and contrasting abruptly with the narrow paler light brown margin, lacking universal veil remnants; margin incurved to flaring upward, distinctly long striate-tuberculate (0.33-0.42 R), easily cracking in age, non-appendiculate; context 1-2 mm thick above stipe, soft, white to whitish (1A1), unchanging. Lamellae 4-6 mm wide, nearly free to adnexed, crowded, yellowish white to pale yellow (3A2-3) in aspect and greyish white (lighter than 1B1) in side view, marginate, with lamellar edge orange white to orange grey $(5 \mathrm{~A} 2-5 \mathrm{~B} 2)$, minutely eroded; lamellulae of 2-3 lengths, slightly truncate to truncate. Stipe 180-200 × 9-15 mm, cylindrical, slightly tapering upwards and expanded at apex, yellowish white to yellowish grey background (3A1-3B2), often covered with dense fibrils or fine canescence, greyish yellow (4B3), unchanging when bruised; context hollow, slightly chambered, cottony where stuffed, yellowish white to brownish grey (3A1, paler than 5C2), unchanging when cut. Bulb absent. Universal veil on stipe base saccate volva, 49-51 mm from base of stipe to highest point of limb, membranous, closed around stipe, 2-4 mm thick, slightly tough; outer surface white to yellowish white (1A1-2), upper margin yellowish white (darker than 1A2), inner surface greyish white (1B1). Partial veil absent. Spore print white. Odor and taste not recorded. 
Lamellar trama bilateral, divergent; mediostratum 40-50 $\mu \mathrm{m}$ wide; filamentous hyphae 4-8 $\mu \mathrm{m}$ wide, branching, hyaline, with slightly inflated elements; vascular hyphae $3-5 \mu \mathrm{m}$ wide, flexuose, common to frequent, scattered; no clamps observed. Subhymenium $28-48 \mu \mathrm{m}$ thick in 3-4 layers, with subglobose to ovoid cells dominating, occasionally broadly cylindrical, 7-12 $\times 6-11$ $\mu \mathrm{m}$, subtended by concatenated cylindrical segments or partially inflated hyphae. Basidia 57-61 $\times$ 11-18 $\mu \mathrm{m}$, narrowly clavate to clavate, mostly 4-, occasionally 2 -spored, with sterigmata up to 6.6 $\mu \mathrm{m}$ long; no clamps observed at base of basidia. Basidiospores [100/2/1] (7.6-) 7.9-10.7 (-11.6) $\times$ (6.7-) 7-9.7 (-10.3) $\mu \mathrm{m},\left(\mathrm{L}^{\prime}=9.0 \mu \mathrm{m} ; \mathrm{W}^{\prime}=8.3 \mu \mathrm{m} ; \mathrm{Q}=(1.00-) 1.01-1.18(-1.20)\right.$; $\mathrm{Q}^{\prime}=1.09 \pm$ 0.06), smooth, hyaline, colorless, thin-walled, inamyloid, globose to subglobose, rarely broadly ellipsoid; apiculus rather variable, sublateral, small, up to $1.2 \mu \mathrm{m}$ long, cylindric to truncate-conic; contents monoguttulate. Lamellar edge sterile; filamentous hyphae 3-7 $\mu \mathrm{m}$ wide, hyaline, colorless or pale yellow, thin-walled; inflated cells dominating, mostly globose to subglobose and sometimes ovoid, 10-23 $\times$ 9-17(-25) $\mu \mathrm{m}$, colorless, thin-walled. Pileipellis up to 212-338 $\mu \mathrm{m}$ thick, made of two layers; suprapellis $43-88 \mu \mathrm{m}$ thick, gelatinized, with filamentous undifferentiated hyphae 2-4 $\mu \mathrm{m}$ wide, sometimes branching, colorless, thin-walled; subpellis 169-250 $\mu \mathrm{m}$ thick, not gelatinized, with filamentous undifferentiated hyphae 3-5 $\mu \mathrm{m}$ wide, sometimes branching, with intracellular yellowish-brown pigments, thin-walled; vascular hyphae 2-6 $\mu \mathrm{m}$ wide, flexuose, branching, coiling, common to frequent, scattered; no clamps observed. Pileus context filamentous hyphae 3-5 $\mu \mathrm{m}$ wide, interwoven; mixed with abundant inflated cells, with terminal broadly clavate to clavate 35-60 × 70-90 $\mu \mathrm{m}$ cells, thin-walled; vascular hyphae 3-5 $\mu \mathrm{m}$ wide, sinuous, frequent; no clamps observed. Universal veil on stipe base exterior surface gelatinized, with filamentous hyphae 5-8 $\mu \mathrm{m}$ wide, interwoven; vascular hyphae 4-5 $\mu \mathrm{m}$ wide, sinuous, rare; interior surface with abundant filamentous hyphae 3-4 $\mu \mathrm{m}$ wide; inflated cells, with terminal subglobose, ovoid to broadly clavate 32-45 $\times 43-58 \mu \mathrm{m}$ cells; vascular hyphae 8-9 $\mu \mathrm{m}$ wide, sinuous, scattered; no clamps observed. Stipe trama longitudinally acrophysalidic; filamentous hyphae undifferentiated 3-5 $\mu \mathrm{m}$ wide, thinwalled, frequently branching; acrophysalides up to 80-396 $\times 18-48 \mu \mathrm{m}$, thin-walled; vascular hyphae 3-15 $\mu \mathrm{m}$ wide, sinuous, rare, scattered; no clamps observed.

Habitat - Scattered on the ground in Fagaceae forest.

Distribution - Currently only known from northern Thailand.

Remarks - In the field, A. brunneoumbonata is characterized by a brownish black umbonate pileus, that has a dark radially fibrillose appearance from center toward margin, and a central darkly colored disc that is exceptionally large and which contrasts abruptly with the narrow paler light brown margin near the marginal striations. Not many species have a pileus that is strikingly dark, radially fibrillose from center toward margin like A. brunneoumbonata.

Amanita brunneoumbonata can be compared with other species with similar macro characteristics including an umbonate pileus with distinctive, strongly contrasting zone at the disc, somber pileus colors, and distinctly long striations. Amanita brunneoumbonata is similar to A. umbrinolutea (Secr. ex Gillet) Bataille, originally described from Switzerland, and widely distributed in Europe, but the latter is associated with Pinus and Picea spp., rather than Fagaceae and Dipterocarpaceae. Moreover, A. umbrinolutea has a stipe covered with fibrils in a banded pattern and a pileus lacking the virgate or dark radially fibrillose surface of A. brunneoumbonata. Basidiospores of both A. brunneoumbonata and A. umbrinolutea are subglobose to globose or broadly ellipsoid $\left(\mathbf{Q}^{\prime}=1.08-1.09 \mu \mathrm{m}\right)$. However, A. umbrinolutea has larger basidiospores, [(9.5-) 10.5-13.4 (-17.2) $\times(8.5-)$ 9.5-12.5 (-14.8) $\mu \mathrm{m}$ (Bataille 1910)] compared to those of $A$. brunneoumbonata, [(7.6-) 7.9-10.7 (-11.6) $\times(6.7-)$ 7-9.7 (-10.3) $\mu \mathrm{m}]$. Amanita brunneoumbonata also shares similarity with A. magnivolvata Aalto, originally described from Finland and found in mixed forest associated with Populus, Betula, Quercus, and Abies trees. Both species are very large; however, clamps are relatively commonly observed at the base of basidia in A. magnivolvata, while they are absent in A. brunneoumbonata. A. magnivolvata has quite larger spores, [(9.0-) 9.8$15.0(-17.7) \times(7.2-)$ 8.4-12.2 (-15.6) $\mu \mathrm{m}$ (Aalto 1974)], and are subglobose to broadly ellipsoid.

Regarding taxa from South-East Asia, A. brunneoumbonata is similar to A. atrofusca, which was first encountered in China, and also has an obtusely umbonate, dark brown pileus, with a 
darker colored zone at the disc, but it has shorter marginal striations $(0.2-0.3 \mathrm{R})$. Moreover, the stipe of A. atrofusca is densely covered with dark brown, furfuraceous squamules, the volva is saccate at the stipe base and is covered with brownish spots on the outer surface, and the basidiospores are slightly larger, [(9.5-) 11.0-14.5 (-15.0) × (8.5-) 11.0-14.5 (-15.0) $\mu \mathrm{m}$; Yang 1997]. Amanita brunneofuliginea Zhu L. Yang, originally reported from China (Yang 1997) differs from A. brunneoumbonata by having white to dirty white patch-like universal veil remnants on its pileus; a white to dirty white saccate volva that is covered with leather-colored squamules on the outer surface that shows a cracked pattern, as well as having larger basidiospores [(10.0-) 10.5$13.0(-14.0) \times(9.0-) 9.5-12.0(-12.5) \mu \mathrm{m}]$ that are subglobose to broadly ellipsoid $\left(\mathrm{Q}^{\prime}=1.13\right)$. While both species are distinctly long striate, A. brunneofuliginea is striate-tuberculate (0.2-0.4 R) but the striations of $A$. brunneoumbonata are sulcate and slightly longer 0.33-0.42 R (Yang 1997). A. brunneoumbonata has so far been found associated with Dipterocarpus and Shorea trees, whereas A. atrofusca is found in association with Picea and Betula, and A. brunneofuliginea is found in association with Quercus and Abies, both in subalpine to alpine regions of southwestern China.

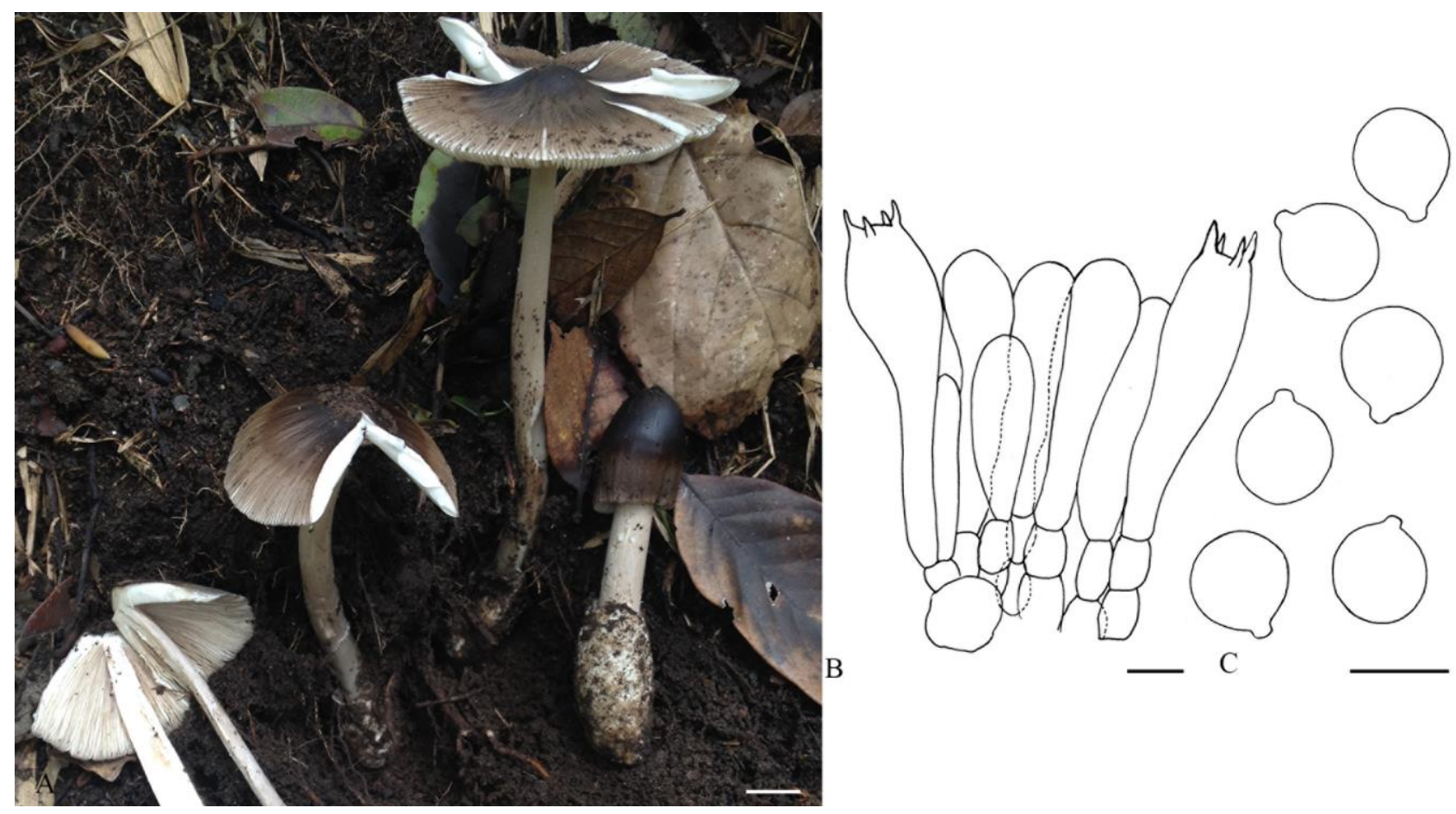

Figure 5 - Amanita brunneoumbonata (BZ2015-67). A Basidiomata. B Hymenium and subhymenium. C Basidiospores. Scale bars: $A=2 \mathrm{~cm} ; \mathrm{B}, \mathrm{C}=10 \mu \mathrm{m}$.

Amanita cinnamomea Thongbai, Raspé \& K.D. Hyde, sp. nov.

Fig. 6

MycoBank number MB821505; Facesoffungi number FoF03378

Type - Thailand: Prov. Chiang Mai: Mae On District, Huay Kaeo, elev. 765 m, N18 $52.15^{\prime \prime}$ E99¹8.23", 15 August 2015, B. Thongbai BZ2015-45 (MFLU 15-3340 - holotype; BBH 42251isotype).

Additional specimens examined - Thailand: Prov. Chiang Mai: Mae On District, Huay Kaeo, elev. 800 m, N 18 52'11" E99¹8'8", 15 Aug. 2015, B. Thongbai BZ2015-48 (MFLU 15-3343, BBH 42252); ibid., elev. 800 m, N1852'13" E99¹8'6", 15 Aug. 2015, B. Thongbai BZ2015-49 (MFLU 15-3344, BBH 42253).

Etymology - "cinnamomea" refers to the cinnamon color of the lamellar edge and pileus.

Basidiomata medium-sized. Pileus $65-75 \mathrm{~mm}$ in diameter, parabolic to hemispheric when young, convex to plane at maturity, often depressed at center, then also with low umbo, dull, dry to slightly viscid when moist, brown to cinnamon, sunburn or caramel (5D6, 6D4-8, 6E8), often with 
cinnamon bloom at center, contrasting abruptly with paler colors, light orange or paler sunburn, towards margin; universal veil remnants present or absent, if present as a single large patch when young, orange white (5A2) with large floccose cinnamon-colored warts; margin arched when young, straight to decurved when mature, distinctly long striate-tuberculate $(0.45-0.46 \mathrm{R})$, nonappendiculate; context 2-4 mm thick above stipe, soft, white to whitish (1A1), unchanging. Lamellae 4-5 mm wide, free, close to slightly crowded, pale yellow, cream (4A2-3) in aspect and yellowish white (3A2-3) in side view, marginate, with lamellar edge cinnamon brown (6D6), distinctly eroded; lamellulae of 3-6 lengths, slightly truncate to truncate. Stipe 130-150 × 6-15 $\mathrm{mm}$, subcylindrical, slightly tapering upwards, flaring at apex, white to orange-white background (lighter than 4A2), covered with dense fibrillose squamules on upper half, darker and forming a fibrillose squamules wavy or flame pattern, orange-grey to greyish orange (5B2-6B3) on the surface, unchanging when bruised; context hollow or partially stuffed, then soft, white to yellowish white (3A1-2), unchanging when cut. Bulb absent. Universal veil on stipe base saccate volva, 28$33 \mathrm{~mm}$ from base of stipe to highest point of limb, membranous, 2-3 $\mathrm{mm}$ thick, slightly tough; outer surface white to orange-white (5A1-2), with large floccose, orange-white (cinnamon, darker than 4A2) warts, upper margin often light brownish orange (6B2), inner surface pale yellowish white (3B2). Partial veil absent. Spore print white. Odor and taste not recorded.

Lamellar trama bilateral, divergent; mediostratum 45-60 $\mu \mathrm{m}$ wide; filamentous hyphae 8-10 $\mu \mathrm{m}$ wide, branching, hyaline, with slightly inflated elements; no vascular hyphae observed. Subhymenium 30-40 $\mu \mathrm{m}$ thick in 3-4 layers, with subglobose to ovoid cells dominating, 10-20 $\times$ 8-12 $\mu \mathrm{m}$, subtended by concatenated partially inflated hyphal segments. Basidia 50-69 × 14-20 $\mu \mathrm{m}$, narrowly clavate to clavate, mostly 4-, occasionally 2 -spored, with sterigmata up to $5 \mu \mathrm{m}$ long; no clamps observed at base of basidia. Basidiospores [100/2/3] (8.8-) 9.2-12.5 (-12.9) $\times(8.6-)$ 8.9-11.4 (-12.1) $\mu \mathrm{m},\left(\mathrm{L}^{\prime}=10.9 \mu \mathrm{m} ; \mathrm{W}^{\prime}=10.07 \mu \mathrm{m} ; \mathrm{Q}=(1.01-) 1.02-1.14(-1.16) ; \mathrm{Q}^{\prime}=1.09 \pm\right.$ 0.06), smooth, hyaline, colorless, thin-walled, inamyloid, globose to subglobose, rarely broadly ellipsoid; apiculus rather variable, sublateral, small, up to $2 \mu \mathrm{m}$ long, truncate-cylindric to truncateconic; contents monoguttulate. Lamellar edge sterile; filamentous hyphae 3-7 $\mu \mathrm{m}$ wide, hyaline, colorless or sometimes pale yellow, thin-walled; inflated cells dominating, mostly globose to subglobose, and sometimes ovoid, 10-25 × 8-16 (-22) $\mu \mathrm{m}$, colorless, thin-walled. Pileipellis made of two layers, up to 70-100 $\mu \mathrm{m}$ thick; suprapellis up to $40-50 \mu \mathrm{m}$ thick, gelatinized, with filamentous undifferentiated hyphae 3-10 $\mu \mathrm{m}$ wide, colorless, thin-walled; subpellis 30-50 $\mu \mathrm{m}$ thick, not gelatinized, with filamentous undifferentiated hyphae 4-10 $\mu \mathrm{m}$ wide, branching, thinwalled, with pale yellow intracellular pigments; vascular hyphae 8-9.5 $\mu \mathrm{m}$ wide, flexuose, branching, coiling, common to frequent, scattered; no clamps observed. Pileus context loosely interwoven filamentous hyphae 3-5 $\mu \mathrm{m}$ wide; abundant inflated cells and terminal ovoid to broadly clavate to clavate $78-118 \times 36-54 \mu \mathrm{m}$ cells, thin-walled; vascular hyphae 3-5 $\mu \mathrm{m}$ wide, sinuous, rare, scattered; no clamps observed. Universal veil at stipe base exterior surface gelatinized, with interwoven filamentous hyphae 5-8 $\mu \mathrm{m}$ wide, sometime mixed with globose to subglobose cells; vascular hyphae 5-6 $\mu \mathrm{m}$ wide, sinuous, rare; interior surface with filamentous hyphae 5-8 $\mu \mathrm{m}$ wide, dominating, mixed with inflated cells, with terminal clavate to broadly clavate 70-90 $\times 60$ $65 \mu \mathrm{m}$ cells; vascular hyphae 8-9 $\mu \mathrm{m}$ wide, sinuous, scattered; no clamps observed. Stipe trama longitudinally acrophysalidic; filamentous hyphae undifferentiated 3-8 $\mu \mathrm{m}$ wide, thin-walled, frequently branching; acrophysalides up to $250-450 \times 25-35 \mu \mathrm{m}$, thin-walled; vascular hyphae 6-7 $\mu \mathrm{m}$ wide, sinuous, rare, scattered; no clamps observed.

Habitat - Scattered on the ground in Fagaceae forest.

Distribution - Currently only known from northern Thailand.

Remarks - Amanita cinnamomea is characterized by a brown to cinnamon, sunburn or caramel pileus, often with darker cinnamon bloom at center, and a markedly paler sunburn or light orange margin, universal veil remnants that are often present when young as a single large orange white patch, with large cinnamon colored floccose granules that also can be observed on the slightly thick and tough saccate volva. Amanita cinnamomea has distinctly marginate lamellae with cinnamon brown and beaded or eroded edge. Tulloss (2000) provided a short key of Amanita 

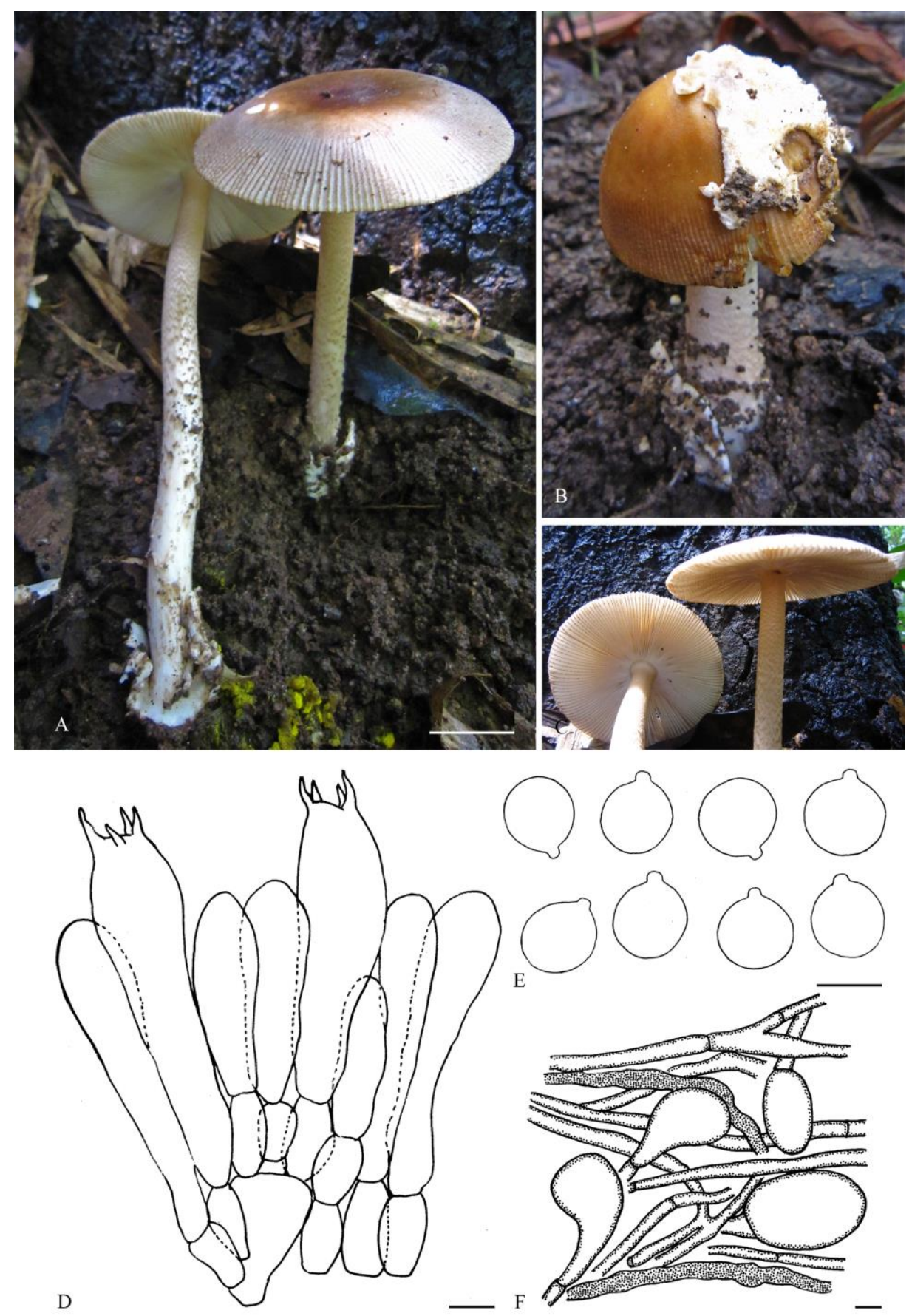

Figure 6 - Amanita cinnamomea (BZ2015-45). A-C Basidiomata. D Hymenium and subhymenium. E Basidiospores. F Section of velar remnants from pileus. Scale bars: A = $2 \mathrm{~cm}$; D$\mathrm{F}=10 \mu \mathrm{m} ; \mathrm{B}-\mathrm{C}$ not to scale.

section Vaginatae, in which A. cinnamomea would key out in stirps Fulva on the basis of pileus marginal striations usually $>0.2 \mathrm{R}$, the pileipellis $<100 \mu \mathrm{m}$ thick, and $95 \%$ of spores with Q $\leq 1.12$. Morphologically, A. cinnamomea is similar to several species that have a brown to redbrown pileus, such as A. aporema Boedijn, A. fulva Fr., A. fuligineodisca Tulloss, Ovrebo \& Halling, and A. orientifulva Zhu L. Yang, M. Weiss \& Oberw. However, A. aporema, which was originally described from Indonesia, has clamp connections at the base of the basidia. The presence of clamps in this taxon raised a question whether A. aporema belong in sect. Caesareae or in sect. Vaginatae (Yang et al. 2004). It should be noted that the type specimen of A. aporema is not in good condition and is preserved in alcohol (Yang et al. 2004). Amanita fuligineodisca described from Colombia, A. fulva, originally described from Germany and widely recorded in Europe and 
North America, and A. orientifulva, originally described from China (Yang et al. 2004) differ from A. cinnamomea in having umbonate pilei that never become depressed at maturity. Also, the strongly cinnamon brown color of the lamellae edge of A. cinnamomea can be used to easily distinguish it from the other four species.

Amanita flavidocerea Thongbai, Raspé \& K.D. Hyde, sp. nov.

Fig. 7

MycoBank number MB821508; Facesoffungi number FoF0337.

Type - Thailand: Prov. Chiang Mai: Mae On District, Huay Kaeo, elev. 720 m, N18 $51 ' 57^{\prime \prime}$ E 99¹8'10", 16 Aug. 2015, B. Thongbai BZ2015-60 (MFLU 15-3355 - holotype; BBH 42259 isotype).

Additional specimen examined - Thailand: Prov. Chiang Mai: Mae On District, Huay Kaeo, elev. 710 m, N1851'56" E99¹8'9", 16 Aug. 2015, B. Thongbai BZ2015-59 (MFLU 15-3354, BBH 42258).

Etymology - "flavidocerea" refers to the yellowish color and waxy surface of the pileus.

Basidiomata medium-sized. Pileus $65-73 \mathrm{~mm}$ in diameter, parabolic to hemispheric when young, then convex to plano-convex at maturity, often depressed at center, dry, shiny, slightly waxy at first to slightly viscid when moist, pastel yellow, dull yellow to wax yellow (3A3, 3B4-5), darker at center, paler yellow or yellowish white $(2 \mathrm{~A} 2,3 \mathrm{~A} 2)$ towards margin; lacking universal veil remnants; margin decurved to flaring upward, slightly striate-tuberculate $(0.25-0.28 \mathrm{R})$, nonappendiculate; context $2-4 \mathrm{~mm}$ thick above stipe, soft, pale yellowish or white (2A1), unchanging. Lamellae 4-5 mm wide, free, close to nearly crowded, yellowish white (3A2-3) in aspect and dull white in side view, marginate, with lamellar edge greyish yellow (lighter than 1B3); lamellulae of 3-6 lengths, attenuate. Stipe 83-95 × 10-12 mm, cylindrical, slightly tapering upwards, orange grey to greyish orange (5B2-3) background, becoming brownish grey (5C3) with age, often covered with yellowish white to yellowish grey $(3 \mathrm{~A} 2,3 \mathrm{~B} 2)$ minute flocculae on upper half, white to dull white (1A1) fibrillose squamules or fine flocculae on lower half, slightly translucent, unchanging when bruised; context hollow or partially stuffed, soft, yellowish white (3A2), unchanging when cut. Bulb absent. Universal veil on stipe base saccate volva, 26-31 $\mathrm{mm}$ from base of stipe to highest point of limb, membranous, closed around stipe, thin, flimsy; outer surface white (1A1), inner surface yellowish white (3A2). Partial veil absent. Spore print white. Odor and taste not recorded.

Lamellar trama bilateral, divergent; mediostratum 60-80 $\mu \mathrm{m}$ wide; filamentous hyphae 5-6 $\mu \mathrm{m}$ wide, branching, hyaline, with slightly inflated elements; no vascular hyphae observed. Subhymenium 36-60 $\mu \mathrm{m}$ thick in 3-4 layers, with subglobose to ovoid cells dominating, 12-15 $\times$ 11-14 $\mu \mathrm{m}$, subtended by concatenated partially inflated hyphal segments. Basidia $45-56 \times 12-18$ $\mu \mathrm{m}$, narrowly clavate to clavate, mostly 4-, occasionally 2 -spored, with sterigmata up to $5 \mu \mathrm{m}$ long; no clamps observed at base of basidia. Basidiospores [100/2/2] (8.7-) 9.0-12.1 (-12.8) $\times(8.3-)$ 8.6-11.7 (-12.4) $\mu \mathrm{m},\left(\mathrm{L}^{\prime}=10.46 \mu \mathrm{m} ; \mathrm{W}^{\prime}=9.94 \mu \mathrm{m} ; \mathrm{Q}=1.0-1.12(-1.18) ; \mathrm{Q}^{\prime}=1.04 \pm 0.04\right)$, smooth, hyaline, colorless, thin-walled, inamyloid, globose to subglobose, rarely broadly ellipsoid; apiculus rather variable, sublateral, small, up to $2 \mu \mathrm{m}$ long, cylindric to truncate-conic; contents monoguttulate or occasionally granular. Lamellar edge sterile; filamentous hyphae 3-7 $\mu \mathrm{m}$ wide, hyaline, colorless or sometimes pale yellow, thin-walled; inflated cells dominating, mostly globose to subglobose and sometimes ovoid 15-22 $\times 20-28 \mu \mathrm{m}$, colorless, thin-walled. Pileipellis up to 120-170 $\mu \mathrm{m}$ thick, made of two layers; suprapellis up to 70-100 $\mu \mathrm{m}$ thick, gelatinized, with filamentous undifferentiated hyphae 3-5 $\mu \mathrm{m}$ wide, interwoven, colorless, thin-walled; subpellis 50$70 \mu \mathrm{m}$ thick, not gelatinized, with filamentous undifferentiated hyphae 3-6 $\mu \mathrm{m}$ wide, frequently branching, with intracellular yellowish brown pigments, thin-walled; vascular hyphae 3-8 $\mu \mathrm{m}$ wide, flexuose, branching, coiling, common to frequent, scattered; no clamps observed. Pileus context filamentous hyphae 3-5 $\mu \mathrm{m}$ wide, frequently branching; mixed with abundant inflated cells, with terminal broadly clavate to clavate 40-65 × 80-90 $\mu \mathrm{m}$ cells, thin-walled; vascular hyphae 6-7 $\mu \mathrm{m}$ wide, sinuous, rare, scattered; no clamps observed. Universal veil on stipe base exterior surface gelatinized, with filamentous hyphae 6-16 $\mu \mathrm{m}$ wide, interwoven; vascular hyphae 5-7 $\mu \mathrm{m}$ wide, 
sinuous, rare, scattered; interior surface with abundant filamentous hyphae 5-8 $\mu \mathrm{m}$ wide, inflated cells, with terminal ovoid to broadly clavate $65-73 \times 25-34 \mu \mathrm{m}$ cells; vascular hyphae 8-10 $\mu \mathrm{m}$ wide, sinuous, scattered; no clamps observed. Stipe trama longitudinally acrophysalidic; filamentous hyphae undifferentiated 4-5 $\mu \mathrm{m}$ wide, thin-walled, frequently branching; acrophysalides up to $140-210 \times 27-32 \mu \mathrm{m}$, thin-walled; vascular hyphae 4-8 $\mu \mathrm{m}$ wide, sinuous, rare, scattered; no clamps observed.

Habitat - Solitary on the ground in in Fagaceae forest.

Distribution - Currently only known from northern Thailand.
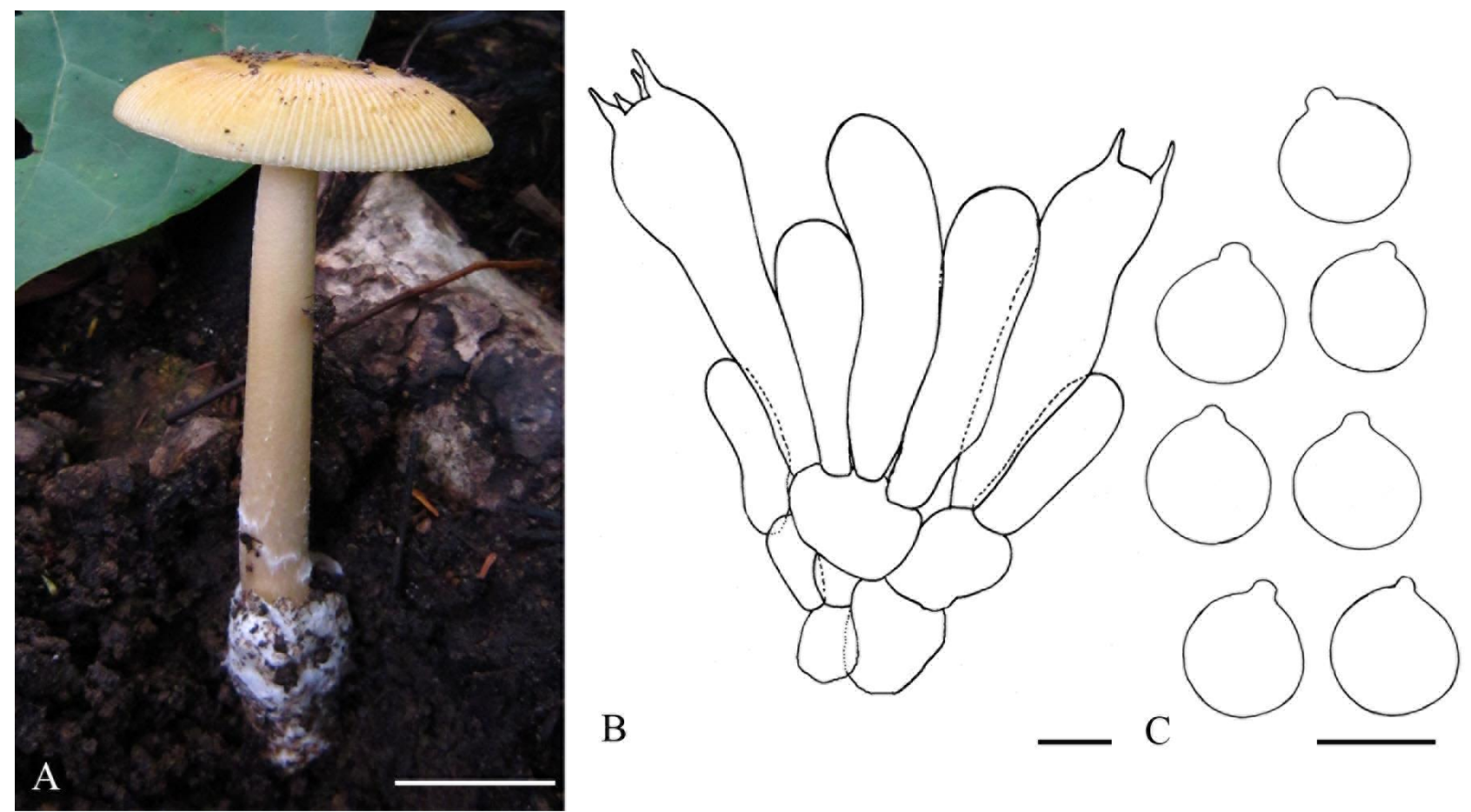

Figure 7 - Amanita flavidocerea (BZ2015-60). A Basidioma. B Hymenium and subhymenium. C Basidiospores. Scale bars: A $=2 \mathrm{~cm} ; \mathrm{B}, \mathrm{C}=10 \mu \mathrm{m}$.

Remarks - The pileus of A. flavidocerea is pastel yellow, dull yellow, depressed at center, and slightly waxy at first when moist. The stipe has an orange grey background, often covered with minute yellowish grey flocculae on upper half, and dull white fibrillose squamules at stipe base, a saccate tightly closed volva with outer surface white and inner surface yellowish white. Those taxa that have similar features and may be confused with A. flavidocerea are A. hamadae Nagas. \& Hongo, A. verrucosivolva Zhu L. Yang, and A. williamsiae Tulloss nom. prov. However, A. flavidocerea can be easily distinguished from the three species above because the latter have a distinctly umbonate pileus, whereas the pileus of A. flavidocerea is often depressed at disc. In addition, the stipe of $A$. hamadae and $A$. verrucosivolva is covered with yellow to orange squamules forming a snakeskin-like pattern. Unfortunately, the stipe squamules have not yet been described in A. williamsiae. Amanita hamadae has basidiospores that are broadly ellipsoid to ellipsoid, Q' = 1.32 (Nagasawa \& Hongo 1984), whereas A. verrucosivolva and A. flavidocerea both have globose to subglobose basidiospores with same $\mathrm{Q}^{\prime}=1.04$. Spores of $A$. verrucosivolva, however, are mostly larger [(9.0-) 10.0-12.5 (-14.0) × (8.5-) 9.0-12.0 (-14.0) $\mu \mathrm{m}$, (Yang 1997)]. Amanita williamsiae, which R. E. Tulloss has seen in fresh condition only once (www.amanitaceae.org/?Amanita+williamsiae; Tulloss \& Yang 2018), seems to be most phenetically related to A. flavidocerea. However, it has larger spores (9.5-) 10.5-14.0 (-15.7) $\times$ (8.2-) 9.0-11.5 (-14.0) $\mu \mathrm{m}$. Marginal striations for A. flavidocerea are 0.25-0.28 R long, while striations are $0.2-0.5 \mathrm{R}$ and $0.3-0.5 \mathrm{R}$ long in A. hamadae and A. verrucosivolva, respectively. Amanita crocea (Quél.) Singer, in addition to being widely distributed in Europe, is different from 
A. flavidocerea because the squamules on the stipe are arranged in a flame-like pattern. The outside surface of the volva of this species is mostly white, but often decorated with rust colored spots.

Amanita flavidogrisea Thongbai, Raspé \& K.D. Hyde, sp. nov.

Fig. 8

MycoBank number MB821510; Facesoffungi number FoF03380.

Type - Thailand, Prov. Chiang Mai, Mae On District, Huay Kaeo, elev.775 m, N 18 $52^{\prime} 9^{\prime \prime}$ E 99¹8'9", 15 Aug. 2015, B. Thongbai BZ2015-44 (MFLU 15-3339 - holotype; BBH 42260 isotype).

Etymology - "flavidogrisea" refers to the yellowish grey to greyish beige ring-like zone on the pileus

Basidiomata small-sized to medium. Pileus $48-53 \mathrm{~mm}$ in diameter, parabolic to hemispheric when young, then convex to plano-convex at maturity, often depressed at center, dry, shiny, slightly viscid when moist, glabrous, yellowish grey to greyish beige (or platinum blonde), slightly olive brown (4B3-4C3, 4D3), lighter at center, yellowish white to yellowish grey (3A1-2) towards margin, lacking universal veil remnants; margin straight or slightly decurved, striate-tuberculate (0.21-0.24 R), non-appendiculate; context 4-5 mm thick above stipe, soft, white to pale yellow (1A1-2), unchanging. Lamellae 4-6 mm wide, free, subdistant to close, yellowish white to pale yellow (3A2-3) in aspect and greyish white or milk white (lighter than 1A2, 2A2) in side view, marginate, with lamellar edge grey, beaded or minutely eroded; lamellulae of 2-3 lengths, nearly truncate. Stipe $72-85 \times 40-53 \mathrm{~mm}$, cylindrical or slightly tapering upwards, white to whitish grey (4B2) background becoming yellowish white (4D2-3) at maturity, often covered with fibrillose squamules or fine flocculae in faint bands at upper half, grey to brownish grey (4D1-2), smooth to minutely flocculose on lower half, dirty white or light yellowish grey (lighter than 4B1), unchanging when bruised; context broadly fistulose to slightly chambered, cottony where stuffed, soft, yellowish white to yellowish grey (3A2-3), unchanging when cut. Bulb absent. Universal veil on stipe base saccate volva, 27-28 mm from base of stipe to highest point of limb, membranous, free from stipe 10-12 mm, 1-3 mm thick, slightly tough; outer surface white or greyish yellow (1A1), inner surface yellowish white (3A2). Partial veil absent. Spore print white. Odor and taste not recorded.

Lamellar trama bilateral, divergent; mediostratum 30-40 $\mu$ m wide; filamentous hyphae 2-3 $\mu \mathrm{m}$ wide, branching, hyaline; vascular hyphae 4-8 $\mu \mathrm{m}$, flexuose, scattered; no clamps observed. Subhymenium 31-63 $\mu \mathrm{m}$ thick in 2-3 layers, with subglobose to ovoid cells dominating, 17-21 $\times$ 15-19 $\mu \mathrm{m}$, subtended by concatenated partially inflated hyphal segments. Basidia 66-70 × 15-17 $\mu \mathrm{m}$, narrowly clavate to clavate, mostly 4-, occasionally 2 -spored, with sterigmata up to $5 \mu \mathrm{m}$ long; no clamps observed at base of basidia. Basidiospores [100/2/1] (9.4-) 9.7-11.4 (-12.1) $\times(8.6-)$ 9.2-11.2 (-11.3) $\mu \mathrm{m},\left(\mathrm{L}^{\prime}=10.7 \mu \mathrm{m} ; \mathrm{W}^{\prime}=10.3 \mu \mathrm{m} ; \mathrm{Q}=1.0-1.1 ; \mathrm{Q}^{\prime}=1.0 \pm 0.03\right)$, smooth, hyaline, colorless, thin-walled, inamyloid, subglobose to subglobose, adaxially flattened; apiculus rather variable, sublateral, small, up to $2 \mu \mathrm{m}$ long, cylindric to truncate-conic; contents monoguttulate or occasionally granular. Lamellar edge sterile; filamentous hyphae 3-7 $\mu \mathrm{m}$ wide, hyaline, colorless or pale yellow, thin-walled; inflated cells dominating, mostly globose to subglobose, sometimes ovoid, 16-23 × 13-15 $\mu \mathrm{m}$, colorless, thin-walled. Pileipellis up to 150-225 $\mu \mathrm{m}$ thick, made of two layers; suprapellis 15-45 $\mu \mathrm{m}$ thick, gelatinized, with filamentous undifferentiated hyphae 1.5-6.5 $\mu \mathrm{m}$ wide, sometimes branching, colorless, thin-walled; subpellis 135-180 $\mu \mathrm{m}$ thick, not gelatinized, with filamentous undifferentiated hyphae 3-8 $\mu \mathrm{m}$ wide, sometimes branching, with intracellular pale brownish pigments, thin-walled; vascular hyphae 4-7 $\mu \mathrm{m}$ wide, flexuose, branching, coiling, scattered; no clamps observed. Pileus context filamentous hyphae 6-7 $\mu \mathrm{m}$ wide, frequency branching, mixed with abundant inflated cells, with terminal broadly clavate to clavate, sometimes broadly globose 60-75 $\times 70-90 \mu \mathrm{m}$ cells, thin-walled; vascular hyphae 7-9 $\mu \mathrm{m}$ wide, sinuous, rare, scattered; no clamps observed. Universal veil on stipe base exterior surface, gelatinized, with filamentous hyphae 5-6 $\mu \mathrm{m}$ wide, interwoven; vascular hyphae 8-9 $\mu \mathrm{m}$ wide, sinuous, rare, scattered; interior surface, with abundant filamentous hyphae 5-10 $\mu \mathrm{m}$ wide; inflated cells, with terminal ovoid to broadly clavate $42-55 \times 35-38 \mu \mathrm{m}$ cells; vascular hyphae $8-9 \mu \mathrm{m}$ wide, sinuous, 
scattered; no clamps observed. Stipe trama longitudinally acrophysalidic; filamentous hyphae undifferentiated 1.5-4.5 $\mu \mathrm{m}$ wide, thin-walled, frequently branching; acrophysalides up to 208-420 $\times 30-40 \mu \mathrm{m}$, thin-walled; vascular hyphae 4-7 $\mu \mathrm{m}$ wide, sinuous, rare, scattered; no clamps observed.

Habitat - Scattered on the ground in mixed Dipterocarpaceae-Fagaceae in Fagaceae forest.

Distribution - Currently only known from northern Thailand.

Remarks - Amanita flavidogrisea was found in loose sandy or soft soil. This fact may have helped to maintain the shape of the distinctly free membranous saccate volva intact, which is most distinctive of the nine species collected in this study. Amanita flavidogrisea is interesting because of the darker yellowish grey to ochraceous ring-like zone on the pileus, between the lighter colored disc, and the lighter colored margin. The stipe is often covered with yellowish grey fibrillose squamules that can form a slight banded pattern on the upper half.
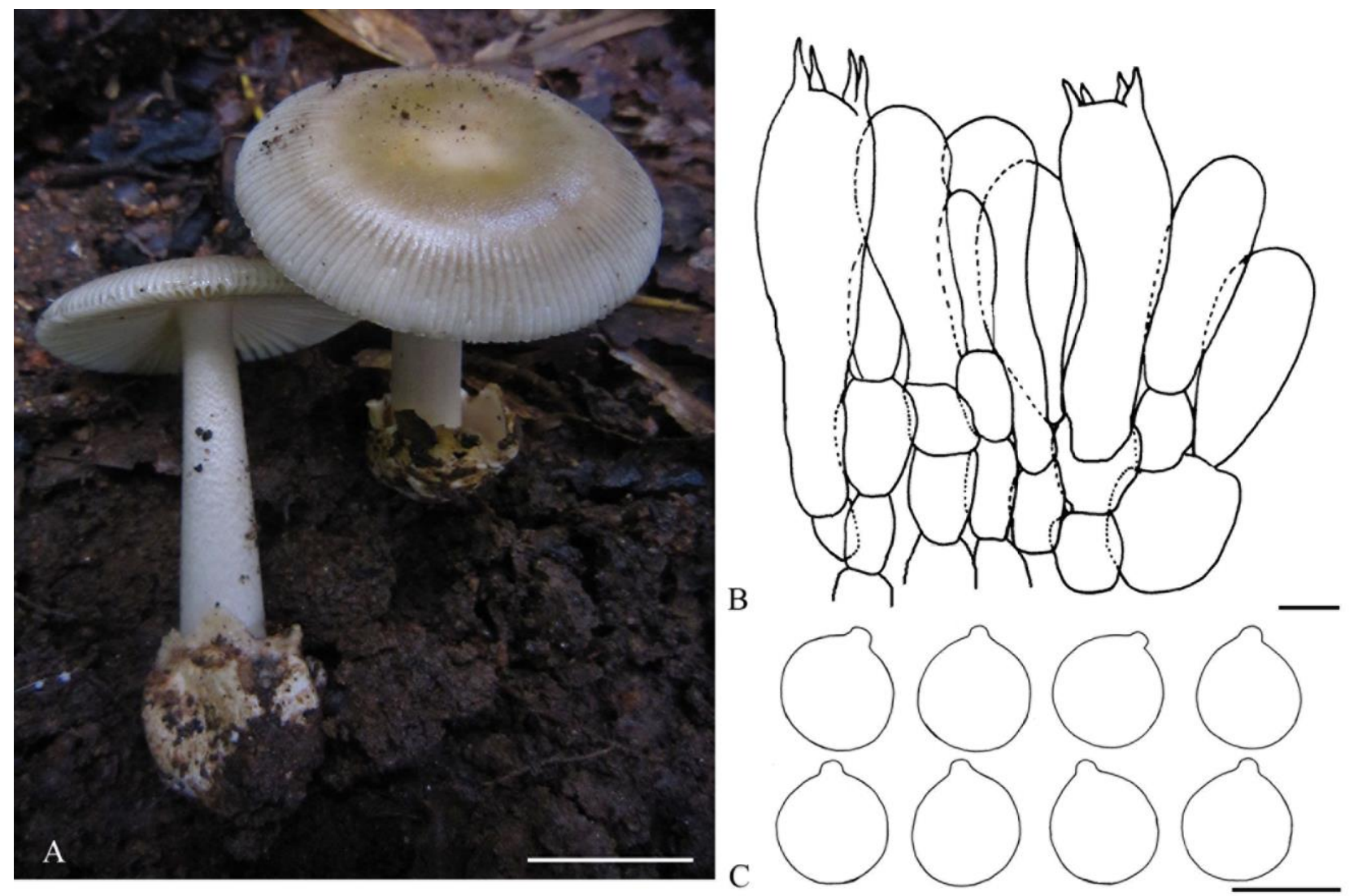

Figure 8 - Amanita flavidogrisea (BZ2015-44). A) Basidiomata. B) Hymenium and subhymenium. C) Basidiospores. Scale bars: $\mathrm{A}=2 \mathrm{~cm} ; \mathrm{B}, \mathrm{C}=10 \mu \mathrm{m}$.

In the field, Amanita flavidogrisea is similar to other species with a yellowish grey to ochraceous pileus, which are often noted to be variable in color, including Amanita crocea (Quél.) Singer, A. hamadae Nagas. \& Hongo, A. nivalis Grev., A. populiphila Tulloss \& E. Moses, and A. olivaceogrisea Kalaméés. Amanita crocea, in addition to being widely distributed in Europe, is different from A. flavidogrisea because the squamules on the stipe are arranged in a flame-like pattern and it has a membranous saccate volva tightly adherent to the base of the stipe. The outside surface of the volva of this species is mostly white, but often decorated with rust colored spots, and the inner surface is orangish cream. Amanita crocea also has slightly larger spores [(8.0-) 9.4-11.8 $(-18.8) \times(7.5-)$ 8.5-11.0 $(-16.0) \mu \mathrm{m}$; (Singer 1949)], while both species have striations on the pileus margin of similar length $(0.2-0.3 \mathrm{R})$. Amanita hamadae differs from A. flavidogrisea by its stipe, which is distinctly tinged with salmon color and is fibrillose-scaly on the lower third of stipe, and has a volva that is attached only at the very base of the stipe. Moreover, A. hamadae has 
broadly ellipsoid to ellipsoid spores $\left(\mathrm{Q}^{\prime}=1.32\right)$ and longer striations on the margin $[(0.2-0.5 \mathrm{R})$; (Nagasawa \& Hongo 1984)]. Amanita nivalis has a white pileus at first, which becomes grayish or with pale ochraceous tints when mature, concolorous with the closed saccate volva at the stipe base, and has globose to subglobose spores $\left(\mathrm{Q}^{\prime}=1.06\right)$, which are slightly larger $[(8.2-)$ 10.0-13.5 $(-21)$ $\times(7.1-)$ 8.8-12.0 (-19.5) $\mu \mathrm{m}$; (Greville 1822)] than those of A. flavidogrisea. Amanita populiphila is an edible species first found in central and western USA that has a broadly umbonate pileus and occasionally has universal veil remnants that form several small patches, or a single large patch. The white cup-shaped volva in A. populiphila is fragile, easily broken, and easily lost from stipe. Amanita olivaceogrisea is widely distributed in Europe, and has an ochraceous gray pileus with crusty large warts, and a volva with a tendency to become gray from the upper edge down (Tulloss \& Moses 1995).

Amanita luteoparva Thongbai, Raspé \& K.D. Hyde, sp. nov.

Fig. 9

MycoBank number MB821511; Facesoffungi number FoF03381

Type - Thailand: Prov. Chiang Mai: Mae On District, Huay Kaeo, elev. 778 m, N 1852'11" E 99¹8'4", 15 Aug. 2015, B. Thongbai BZ2015-46 (MFLU-153341 - holotype; BBH 42261 isotype).

Etymology - "luteoparva" refers to the yellow color of the stipe and small size of basidioma

Basidioma small-sized. Pileus $38 \mathrm{~mm}$ in diameter, convex to plane at maturity, slightly depressed at center, dry, dull, yellowish grey to greyish yellow or platinum blonde colored (4B23 ), slightly darker at center (darker than 4B4), paler greyish yellow or wheat color towards margin (4A2-3), covered with floccose, slightly shaggy, light yellowish grey (lighter than 5B2) patches, mostly over center, rarely towards margin; margin straight or slightly decurved, minutely striatetuberculate $(0.14 \mathrm{R})$, non-appendiculate; context 1-2 mm thick above stipe, soft, white to whitish (1A1), unchanging. Lamellae 2-3 mm wide, free, close or sub-crowded, with short decurrent line on apex of stipe, yellowish grey (4B2) in aspect and yellowish white to pale yellow (3A2-3) in side view, marginate, with lamellar edge greyish brown (6D3-4), beaded or minutely eroded; lamellulae of 2-3 lengths, slightly truncate. Stipe $69 \times 13 \mathrm{~mm}$, cylindrical or slightly tapering upwards, slightly expanded at apex, light yellow to greyish yellow (4B5-6) background, covered with dense farinose squamules or fine floccules, light brown to greyish brown (6D3-4), unchanging when bruised; context hollow, cottony where stuffed, slightly chambered mostly near lower half, thin, white to yellowish white (3A1-2), unchanging when cut. Bulb absent. Universal veil on stipe base saccate volva, 26-31 mm from base of stipe to highest point of limb, membranous, closed around stipe, thin, flimsy; outer surface white (1A1) on margin of limb, darker than yellowish white (3A12 ), floccose on stipe base, inner surface yellowish white (3A2), with limbus internus placed near middle at point of attachment between stipe and volval limb, covered with farinose, light brown to greyish brown (6B3-4). Partial veil absent. Spore print white. Odor and taste not recorded.

Lamellar trama bilateral, divergent; mediostratum 30-40 $\mu$ m wide; filamentous hyphae 3-6 $\mu \mathrm{m}$ wide, branching, hyaline, with slightly inflated elements; no vascular hyphae observed. Subhymenium 27-54 $\mu \mathrm{m}$ thick in 2-3 layers, with subglobose to ovoid cells dominating, 9-18 $\times 8-$ $10 \mu \mathrm{m}$, subtended by concatenated partially inflated hyphal segments. Basidia $48-55 \times 12-16 \mu \mathrm{m}$, narrowly clavate to clavate, mostly 4-, occasionally 2 -spored, with sterigmata up to $5 \mu \mathrm{m}$ long; no clamps observed at base of basidia. Basidiospores [50/1/1] (7.1-) 7.2-8.9 (-9.2) $\times(7.0-)$ 7.1-8.6 (8.8) $\mu \mathrm{m},\left(\mathrm{L}^{\prime}=8.09 \mu \mathrm{m} ; \mathrm{W}^{\prime}=7.82 \mu \mathrm{m} ; \mathrm{Q}=1.0-1.08 ; \mathrm{Q}^{\prime}=1.04 \pm 0.02\right)$, smooth, hyaline, colorless, thin-walled, inamyloid, globose to subglobose; apiculus rather variable, sublateral, small, up to 2 $\mu \mathrm{m}$ long, cylindric to truncate-conic; contents monoguttulate or occasionally granular. Lamellar edge sterile; filamentous hyphae 3-7 $\mu \mathrm{m}$ wide, hyaline, colorless or pale yellow, thin-walled; mostly globose to subglobose and sometimes ovoid cells dominating, 25-55 × 20-40 $\mu \mathrm{m}$, colorless, thin-walled. Pileipellis up to 35-60 $\mu \mathrm{m}$ thick, gelatinized, filamentous undifferentiated hyphae 2-6 $\mu \mathrm{m}$ wide, sometimes branching, thin-walled; vascular hyphae 2.5-3.5 $\mu \mathrm{m}$ wide, flexuose, branching, coiling, rare scattered; no clamps observed. Pileus context filamentous hyphae 5-6 $\mu$ m wide, frequently branching, abundant inflated cells, with terminal globose to broadly subglobose 
25-43 $\times 22-40 \mu \mathrm{m}$, thin-walled; vascular hyphae 6-7 $\mu \mathrm{m}$ wide, sinuous, rare, scattered; no clamps observed. Universal veil on pileus filamentous hyphae, 3-6 $4 \mathrm{~m}$ wide, occasionally branching, single or in chain with terminal slightly subfusiform to narrowly clavate cells occasionally in chains, 30-53 $\times 15-21 \mu \mathrm{m}$, hyaline, or with intracellular pale brownish pigments, thin-walled; globose to subglobose, sometimes ovoid to obovoid dominating, 28-35 $\times 20-26 \mu \mathrm{m}$; no vascular hyphae observed. Universal veil on stipe base similar to those cells observed in veil remnants on pileus, filamentous hyphae, $3-5 \mu \mathrm{m}$ wide, occasionally branching, with slightly inflated cells, with terminal globose to subglobose, occasional ovoid to obovoid dominating 19-39 × 15-34 $\mu \mathrm{m}$ cells, with intracellular pale brownish-white pigments, thin-walled; no vascular hyphae observed; exterior surface, gelatinized, filamentous hyphae 6-8 $\mu \mathrm{m}$ wide, interwoven, sometimes with intracellular pale brownish white pigments; vascular hyphae 5-9 $\mu \mathrm{m}$ wide, sinuous, rare, scattered; no clamps observed. Stipe trama longitudinally acrophysalidic; filamentous hyphae undifferentiated 3-6 $\mu \mathrm{m}$ wide, thin-walled, frequently branching; acrophysalides up to 80-290 × 15-48 $\mu \mathrm{m}$, thin-walled; vascular hyphae 3.5-5 $\mu \mathrm{m}$ wide, sinuous, rare, scattered; no clamps observed.

Habitat - Solitary on the ground in Fagaceae forest.

Distribution - Currently only known from northern Thailand.
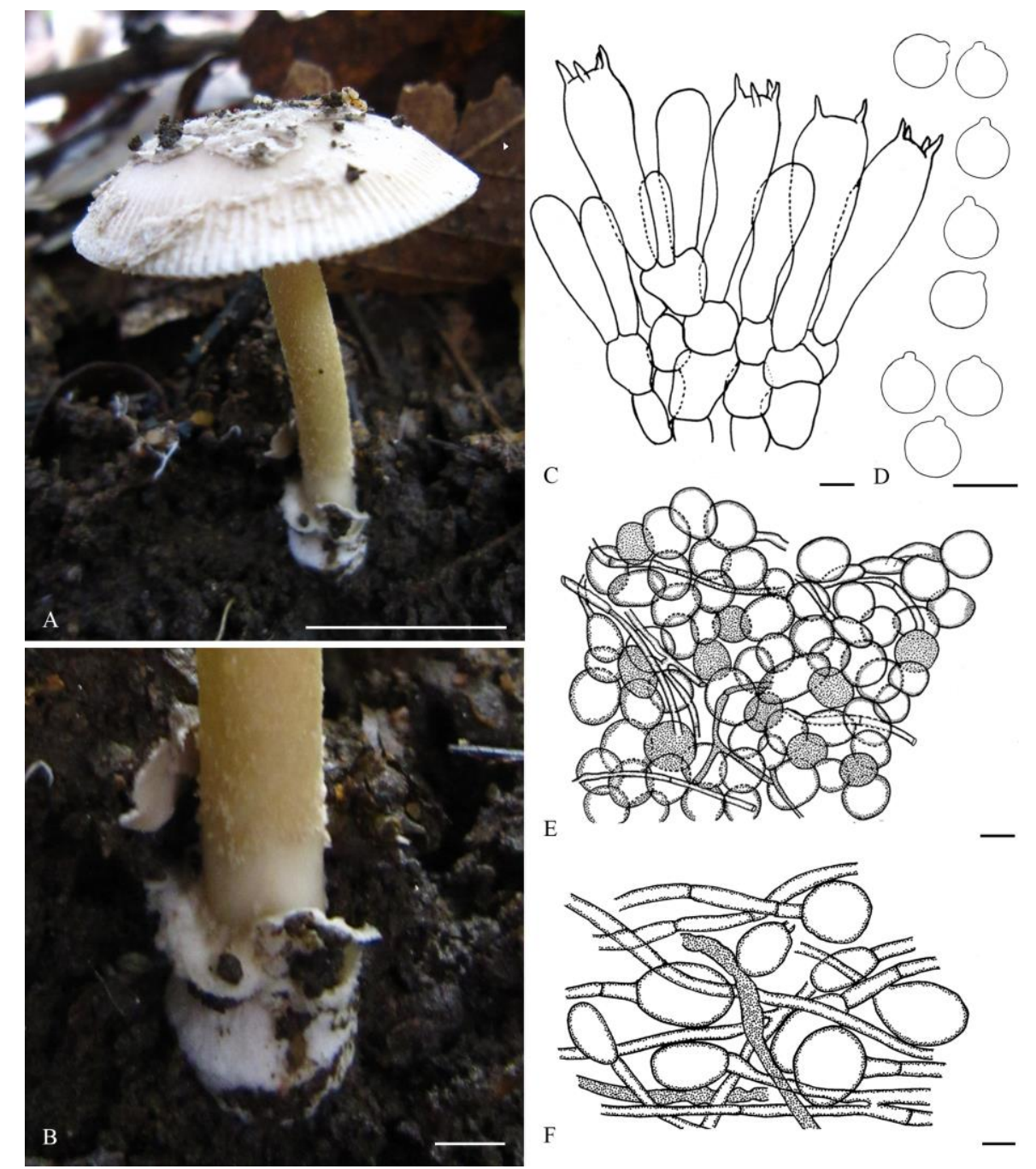

Figure 9 - Amanita luteoparva (BZ2015-46). A Basidiomata. B Universal veil on stipe base. $\mathrm{C}$ Hymenium and subhymenium. D Basidiospores. E Section of velar remnants from pileus. F Longitudinal section of pelius. Scale bars: $A-B=2 \mathrm{~cm} ; C-F=10 \mu \mathrm{m}$.

Remarks - Amanita luteoparva is very unique among species found in Thailand because of its small-sized basidioma with yellow pileus covered with floccose, slightly shaggy patches in both 
young and mature stages. The stipe is covered with dense farinose squamules or fine floccules. Phenetically, A. luteoparva is similar to A. madagascariensis that has warty veil remnants on the pileus and base of the stipe. However, the warty veil remnants in A. madagascariensis form an incomplete belt of the saccate volva, whereas A. luteoparva has a complete belt on the volva. In addition, A. madagascariensis has ellipsoid to elongate basidiospores with Q' $=1.69$ (Tang et al. 2015), while A. luteoparva has globose to subglobose spores. Both have marginal striations on the pileus of the same length $(0.1 \mathrm{R})$. Amanita cinctipes Corner \& Bas, originally described from Singapore, has gray to grayish brown pyramidal warts on the universal veil remnants on the pileus and fibrillose scales forming 2-4 rings on the base of the stipe, as well as a saccate volva that is easily breakable (Corner \& Bas 1962). Moreover, A. cinctipes has longer marginal striations on the pileus $(0.3-0.4 \mathrm{R})$ and globose to subglobose basidiospores $\left(\mathrm{Q}^{\prime}=1.05\right)$ which are larger $[(8.2-11.1$ 7) $\times(7.8-10.1) \mu \mathrm{m}$; (Corner \& Bas 1962)] than those of A. luteoparva. Amanita luteoparva was described from a single small collection and, therefore, more material would be beneficial for further study.

Amanita suborientifulva Raspé, Thongbai, \& K.D. Hyde, sp. nov.

Fig. 10

MycoBank number MB821512; Facesoffungi number FoF03382

Type - Thailand: Prov. Chiang Mai: Meuang District, Doi Suthep Subdistrict, Doi SuthepPui National Park, elev. 1600 m, N18 50'10" E98 53'20", 02 July 2016, O. Raspé OR1276 (SDBRCMU OR1276 - holotype; MFLU 16-2561, BBH 42262 - isotype).

Additional specimen examined - Thailand: Prov. Lampang: along road no. 1252, Parn District, Chaesorn Subdistrict, 15 June 2013, B. Thongbai BZ2013-55 (MFLU 15-0143)

Etymology - "suborientifulva" refers to the similarity with A. orientifulva

Basidiomata - Pileus $47-53 \mathrm{~mm}$ in diameter, parabolic to hemispheric when young, then convex to plano-convex at maturity, sometimes depressed at center, dry, shiny, slightly viscid when moist, glabrous, deep orange to mandarin orange or fulvous orange or brownish orange $(6 \mathrm{~A} 8,6 \mathrm{~B} 8$, $6 \mathrm{D} 8)$, with an fading gradually to paler color at margin, light orange to pale orange (6A3-4) near marginal striations; lacking universal veil remnants; margin straight or slightly decurved, distinctly long striate $(0.38-0.4 \mathrm{R})$, non-appendiculate; context 3.0-3.3 mm thick above stipe, soft, white to pale yellow (1A1-2), unchanging. Lamellae 4-6 mm wide, free, subdistant to close, orange white (5A2, 6A2) in aspect view and yellowish white to pale yellow (3A2-3)in side view, marginate, with lamellar edge concolorous with apex of stipe, brownish orange (lighter than 6C4-5), beaded or minutely eroded; lamellulae of 2-3 lengths, nearly truncate. Stipe 73-92 × 13-33 mm, cylindrical or tapering upwards, orange white to orange grey (6A3-6B3) background becoming dark orange grey (darker than 6B3) at maturity, often covered with fibrillose squamules or fine flocculae, brown to brownish orange (6C4-5), with short decurrent line on apex of stipe; unchanging when bruised; context broadly fistulose to chambered, cottony, soft, yellowish white to yellowish grey (3A2-3), unchanging when cut. Bulb absent. Universal veil on stipe base saccate volva, 31-39 $\mathrm{mm}$ from base of stipe to highest point of limb, membranous, 1-3 mm thick, slightly tough; outer surface brownish orange or as same color as stipe on up to the upper third, elsewhere white or yellowish white (3A2-3), with brownish orange spots or scales on surface, inner surface pale brownish orange (paler than 6C4-5). Partial veil absent. Spore print white. Odor and taste not recorded.

Lamellar trama bilateral, divergent; mediostratum 40-55 $\mu \mathrm{m}$ wide; filamentous hyphae 3-5 $\mu \mathrm{m}$ wide, branching, hyaline; vascular hyphae 4-6 $\mu \mathrm{m}$, flexuose, rare, scattered; no clamps observed. Subhymenium 34-57 $\mu \mathrm{m}$ thick in 2-3 layers, with subglobose to ovoid cells dominating, $17-19 \times 15-16 \mu \mathrm{m}$, subtended by concatenated partially inflated hyphal segments. Basidia 43-62 $\times$ 13-17 $\mu \mathrm{m}$, narrowly clavate to clavate, mostly 4-, occasionally 2 -spored, with sterigmata up to 7 $\mu \mathrm{m}$ long; no clamps observed at base of basidia. Basidiospores [100/2/2] (9.8 -) 9.9-13.3 (-14) $\times$ (8.5-) 8.9-12.3 (-13.1) $\mu \mathrm{m},\left(\mathrm{L}^{\prime}=11.08 \mu \mathrm{m} ; \mathrm{W}^{\prime}=10.4 \mu \mathrm{m} ; \mathrm{Q}=(1.0-)\right.$ 1.01-1.21 (-1.29); $\mathrm{Q}^{\prime}=$ $1.08 \pm 0.07)$, smooth, hyaline, colorless, thin-walled, inamyloid, globose to subglobose or broadly ellipsoid, adaxially flattened; apiculus rather variable, sublateral, small, up to $2 \mu \mathrm{m}$ long, cylindric to truncate-conic; contents monoguttulate or occasionally granular. Lamellar edge sterile; 
filamentous hyphae 3-7 $\mu \mathrm{m}$ wide, hyaline, colorless or pale yellow, thin-walled; inflated cells, with terminal globose to subglobose and sometimes ovoid, 20-60 × 20-35 $\mu \mathrm{m}$ cells, colorless, thinwalled. Pileipellis up to $110-150 \mu \mathrm{m}$ thick, made of two layers; suprapellis $60-80 \mu \mathrm{m}$ thick, gelatinized, with filamentous undifferentiated hyphae 2-5 $\mu \mathrm{m}$ wide, colorless, thin-walled; subpellis 50-70 $\mu \mathrm{m}$ thick, not gelatinized, with filamentous undifferentiated hyphae 2-5 $\mu \mathrm{m}$ wide, branching, with intracellular pale yellowish white pigments, thin-walled; vascular hyphae 4-10 $\mu \mathrm{m}$ wide, flexuose, branching, coiling, scattered; no clamps observed. Pileus context filamentous hyphae 3-5 $\mu \mathrm{m}$ wide, frequently branching; mixed with abundant inflated cells, with terminal broadly clavate to clavate $140-180 \times 40-65 \mu \mathrm{m}$ cells, thin-walled; vascular hyphae 7-9 $\mu \mathrm{m}$ wide, sinuous, frequent, scattered; no clamps observed. Universal veil on stipe base exterior surface, with filamentous hyphae 5-8 $\mu \mathrm{m}$ wide; inflated cells, with terminal subglobose to ovoid $65-95 \times 62-70$ $\mu \mathrm{m}$; vascular hyphae 8-9 $\mu \mathrm{m}$ wide, sinuous, rare, scattered; interior surface, similar with those cells on exterior surface, with abundant filamentous hyphae 5-8 $\mu \mathrm{m}$ wide, inflated cells, with terminal ovoid to broadly clavate $60-75 \times 45-68 \mu \mathrm{m}$ cells; vascular hyphae 8-9 $\mu \mathrm{m}$ wide, sinuous, scattered; no clamps observed. Stipe trama longitudinally acrophysalidic; filamentous hyphae undifferentiated 3-7 $\mu \mathrm{m}$ wide, thin-walled, frequently branching; acrophysalides up to $200-370 \times$ 30-45 $\mu \mathrm{m}$, thin-walled; vascular hyphae 9-12 $\mu \mathrm{m}$ wide, sinuous, rare, scattered; no clamps observed.

Habitat - Scattered on the ground in Fagaceae forest or mixed stands of Fagaceae and Pinus kesiya.

Distribution - Currently only known from northern Thailand.
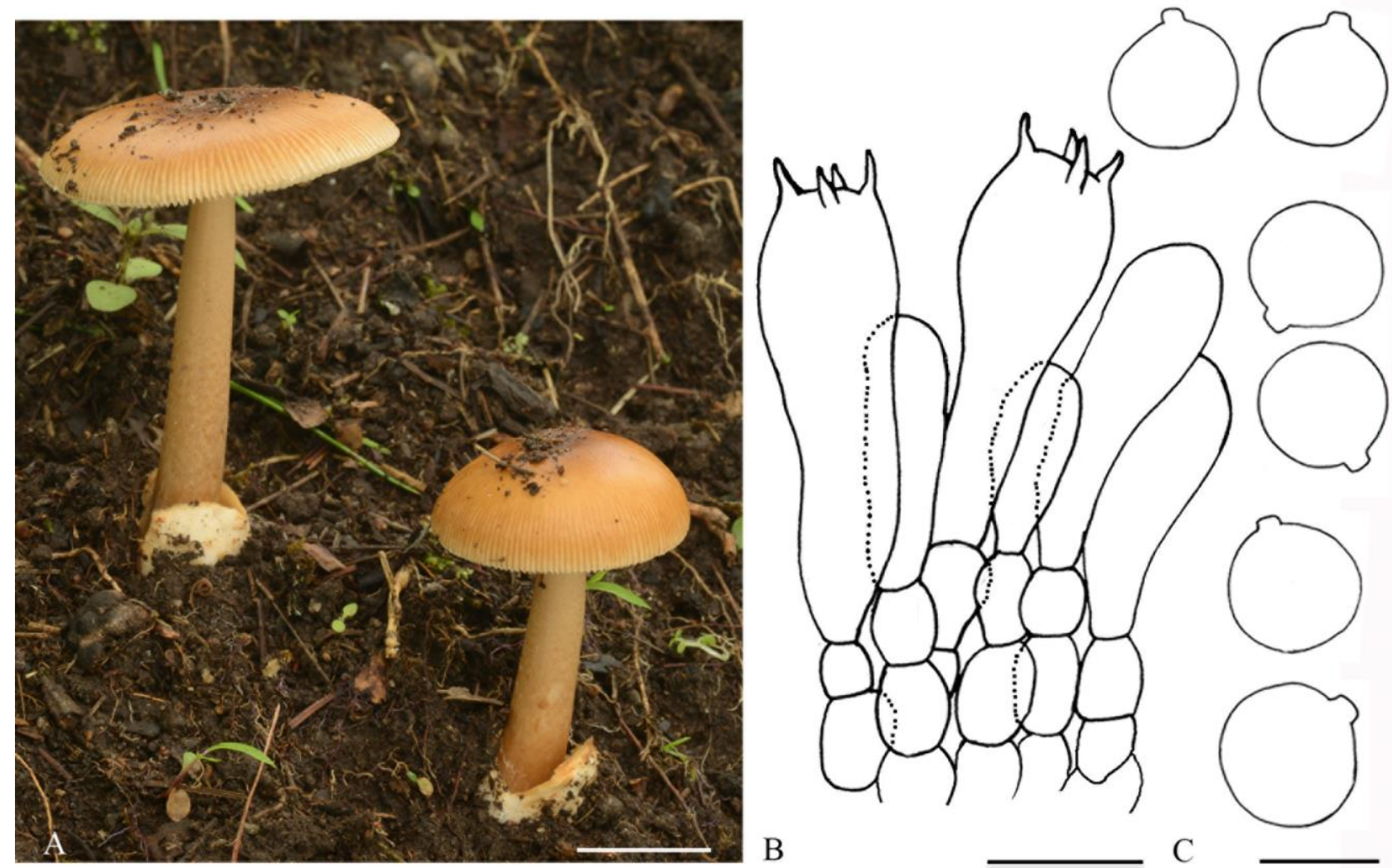

Figure 10 - Amanita suborientifulva (OR1276). A Basidiomata. B Hymenium and subhymenium. C Basidiospores. Scale bars: A= $2 \mathrm{~cm} ; \mathrm{B}, \mathrm{C}=10 \mu \mathrm{m}$.

Remarks - Amanita suborientifulva can easily be recognized by its non-umbonate, orange pileus, which fades gradually to a paler light orange near the distinctly long marginal striations. $A$. suborientifulva also lacks universal veil remnants on the pileus. The stipe has an orange white to orange grey background color becoming dark orange grey at maturity, and is covered with brown to brownish orange fibrillose squamules, has decurrent short lines on the apex, and the saccate volva 
is decorated with brownish orange scales on its surface, which are dense on the upper part. Based on the characteristics used to construct the key of sect. Vaginatae (Tulloss 2005), Amanita suborientifulva would be keyed out in strips Fulva. Amanita suborientifulva looks very comparable to A. orientifulva Zhu L. Yang, M. Weiss \& Oberw., originally described from Southeast Asia (China), in having orange or brownish orange pileus and brownish orange scales on the surface of the upper part of the saccate volva. However, A. orientifulva has an obtusely umbonate pileus, globose to subglobose basidiospores $\left(\mathrm{Q}^{\prime}=1.06\right)$ which larger, $10.0-14.0 \times 9.5-13.0 \mu \mathrm{m}$, and is striate-tuberculate at the margin of the pileus 0.38-0.4 R Yang et al. 2004. Amanita fulva (Schaeff.) Fr., originally described from Europe, A. fuligineodisca Tulloss, Ovrebo \& Halling and A. humboldtii Singer from Colombia, are reminiscent of $A$. suborientifulva in coloration but differ by also having an a umbonate to subumbonate pileus at maturity (Fries 1815, Tulloss et al. 1992). Amanita daimonioctantes Tulloss nom. prov. (www.amanitaceae.org/?Amanita+daimonioctantes, Tulloss \& Yang 2018), also is moderately similar macroscopically to A. suborientifulva. However, the molecular data of both nrITS and nrLSU indicates that the two species are not closely related.

Amanita subovalispora Thongbai, Raspé \& K.D. Hyde, sp. nov.

Fig. 11

MycoBank number MB821513; Facesoffungi number FoF03383.

Type - Thailand: Prov. Chiang Mai: Mae On District, Huay Kaeo, elev. 775 m, N18 $52^{\prime} 10^{\prime \prime}$ E99'18'10", 18 Aug. 2015, B. Thongbai BZ2015-70 (MFLU 15-3366 - holotype; BBH 42250 isotype).

Additional specimen examined - Thailand: Prov. Chiang Mai: Doi Saket District, 30 June 2014, elev.1280 m, N1855'38" E99²1'53", B. Thongbai BZ2014-06 (MFLU 15-0095).

Etymology - "subovalispora" refers to the similarity with A. ovalispora.

Basidiomata small to medium-sized. Pileus $55-60 \mathrm{~mm}$ in diameter, convex to broadly convex, becoming plane at maturity, often depressed at center, dry, dull, slightly viscid and surface shiny when moist, minutely silky, greyish brown to brownish grey or dark grey $(7 \mathrm{E} 3-4,5)$, darker greyish black (slightly darker than 7E5) at center, becoming paler greyish towards margin, lacking universal veil remnants; margin arched when young, incurved to flaring upward when mature, strongly striate-tuberculate $(0.36-0.4 \mathrm{R})$, non-appendiculate; context $1-3 \mathrm{~mm}$ thick above stipe, soft, white to whitish (1A1), unchanging. Lamellae 2-3 mm wide, nearly free to adnexed, close to slightly crowded, yellowish white to pale yellow (3A2-3) in aspect and dull white in side view, marginate, with lamellar edge brownish grey (7D2), minutely eroded; lamellulae of 2-3 lengths, slightly truncate to truncate. Stipe $80-90 \times 9-10 \mathrm{~mm}$, cylindrical or tapering upwards, slightly flaring, with short decurrent line at apex, white to yellowish white (3A1-2) background, often densely covered with fibrillose squamules or fine canescence, bright white (1A1), contrasting with background, not arranged in wavy or flame pattern, unchanging when bruised; context hollow or slightly chambered, mostly near base, cottony where stuffed, white to yellowish white (3A1-2), unchanging when cut. Bulb absent. Universal veil on stipe base saccate volva, 20-28 $\mathrm{mm}$ from base of stipe to highest point of limb, membranous, 2-3 mm thick, flimsy; outer surface white (1A1), floccose to fibrillose-felted, dull white spots on the upper part; inner surface yellowish white (1B2). Partial veil absent. Spore print white. Odor and taste not recorded.

Lamellar trama bilateral, divergent; mediostratum 45-55 $\mu \mathrm{m}$ wide; filamentous hyphae 2-7 $\mu \mathrm{m}$ wide, branching, hyaline, with slightly inflated elements; subfusiform to long ellipsoid or clavate cells dominating, 50-110 × 18-28 $\mu \mathrm{m}$; no vascular hyphae observed. Subhymenium 30-56 $\mu \mathrm{m}$ thick in 3-4 layers, with subglobose to ovoid cells dominating, $10-14 \times 9-12 \mu \mathrm{m}$, subtended by concatenated partially inflated hyphal segments. Basidia 37-46 $\times 10-13 \mu \mathrm{m}$, narrowly clavate to clavate, mostly 4-, occasionally 2-spored, with sterigmata up to $6 \mu \mathrm{m}$ long; no clamps observed at base of basidia. Basidiospores [100/2/2] (8.7-) 8.9-11.4 (-11.7) $\times(8.6-)$ 7.3-8.8 (-9.6) $\mu \mathrm{m},\left(\mathrm{L}^{\prime}=\right.$ $9.97 \mu \mathrm{m} ; \mathrm{W}^{\prime}=8.01 \mu \mathrm{m} ; \mathrm{Q}=(1.06-)$ 1.11-1.42 (-1.48); $\left.\mathrm{Q}^{\prime}=1.25 \pm 0.09\right)$, smooth, hyaline, colorless, thin-walled, inamyloid, broadly ellipsoid to ellipsoid, rarely globose to subglobose, occasionally adaxially flattened; apiculus rather small, up to $1.5 \mu \mathrm{m}$ long, cylindric to truncateconic; contents monoguttulate. Lamellar edge sterile; filamentous hyphae 3-7 $\mu \mathrm{m}$ wide, hyaline, 
colorless or sometimes pale yellow, thin-walled; mixed with globose to subglobose, sometimes ovoid cells dominating, 18-28 × 13-22 $\mu \mathrm{m}$, colorless, thin-walled; vascular hyphae 3-5 $\mu \mathrm{m}$ wide, sinuous, rare, scattered. Pileipellis up to 147-240 thick, made of two layers; suprapellis 30-82 $\mu \mathrm{m}$ thick, gelatinized, with filamentous undifferentiated hyphae 2.5-6 $\mu \mathrm{m}$ wide, often branching, colorless, thin-walled; subpellis 117-158 $\mu \mathrm{m}$ thick, not gelatinized, with filamentous undifferentiated hyphae 2.5-6 $\mu \mathrm{m}$ wide, often branching, with intracellular pale yellowish-white pigments, thin-walled; vascular hyphae 2-6 $\mu \mathrm{m}$ wide, often branching, coiling, common to frequent, scattered; no clamps observed. Pileus context gelatinized, interwoven filamentous hyphae 3-5 $\mu \mathrm{m}$ wide, with inflated cells dominating, with terminal broadly clavate to clavate $120-150 \times$ 30-60 $\mu \mathrm{m}$ cells, thin-walled; vascular hyphae 4-6 $\mu \mathrm{m}$ wide, sinuous, rare. Universal veil on stipe base exterior surface gelatinized, with filamentous hyphae 3-5 $\mu \mathrm{m}$ wide, interwoven; vascular hyphae 5-6 $\mu \mathrm{m}$ wide, sinuous, frequent; interior surface with abundant filamentous hyphae 7-10 $\mu \mathrm{m}$ wide, inflated cells, with terminal subglobose to broadly clavate $70-75 \times 50-65 \mu \mathrm{m}$ cells; vascular hyphae 5-9 $\mu \mathrm{m}$ wide, sinuous, scattered; no clamps observed. Stipe trama longitudinally acrophysalidic; filamentous hyphae undifferentiated 3-11 $\mu \mathrm{m}$ wide, thin-walled, frequently branching; acrophysalides up to $167-278 \times 26-33 \mu \mathrm{m}$, thin-walled; vascular hyphae 3.5-7.5 $\mu \mathrm{m}$ wide, sinuous, rare, scattered; no clamps observed.

Habitat - Solitary on the ground in Fagaceae or mixed Dipterocarpaceae-Fagaceae forest.

Distribution - Currently only known from northern Thailand.
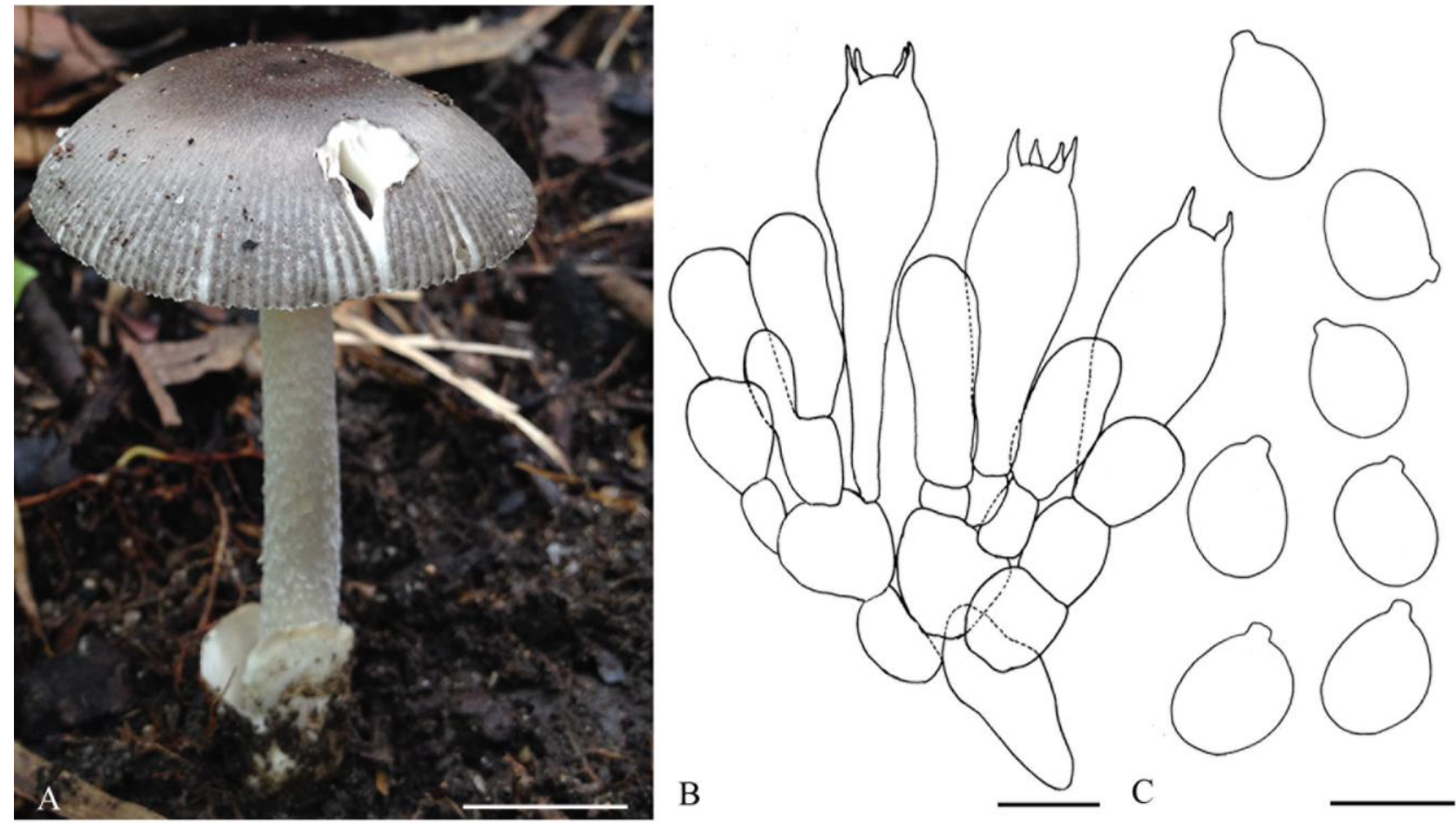

Figure 11 - Amanita subovalispora (BZ2015-70). A Basidioma. B Hymenium and subhymenium. C Basidiospores. Scale bars: A $=2 \mathrm{~cm} ; \mathrm{B}, \mathrm{C}=10 \mu \mathrm{m}$.

Remarks - Out of the nine new species in sect. Vaginatae that are described in this study, $A$. subovalispora is one of only three having broadly ellipsoid to ellipsoid basidiospores. Macromorphologically, Amanita subovalispora is characterized by a minutely silky pileus surface that is greyish brown to brownish grey or dark grey, darker greyish black at center, paler greyish towards margin. The stipe is notable for its short decurrent lines at the apex, and is covered with densely fibrillose squamules or fine canescence, and is slightly shiny. Amanita ovalispora is the most phenetically similar to A. subovalispora in that both have a small pileus that is depressed at 
the center, and broadly ellipsoid to ellipsoid basidiospores with same $\mathrm{Q}^{\prime}=1.25-1.3$. However, $A$. ovalispora has a lighter gray, glabrous pileus surface that is occasionally umbonate, covered with membranous universal veil remnants with longer striations 0.4-0.6 R (Yang 1997, Sanmee et al. 2008), whereas A. subovalispora has a minutely silky pileus surface that lacks universal veil remnants. In addition, the filamentous hyphae structures in lamellar edge contained intracellular pale yellow pigments in A. subovalispora while not observed pigment or colorless in A. ovalispora. Although A. subovalispora and A. ovalispora are similar in micro and macro characters, the Blast results indicated that the two are not closely related. However, there is only one ITS sequence available on GenBank for A. ovalispora, GenBank number FJ441041 (unpublished data) with 91.38 $\%$ identity. Morphologically, A. subovalispora is also similar to A. angustilamellata (Höhn.) Boedijn and A. ovalispora Boedijn, both originally described from Indonesia (Boedijn 1951), and possessing similar somber colors of the pileus, i.e. ranging from smoke brown, smoky-gray, gray to dark gray. However, A. angustilamellata differs from A. subovalispora by having a sub-umbonate pileus, with white or sometimes pale pinkish buff lamellae, stipe with indistinct dark fibrils near the base, universal veil remnants on the pileus that are either absent or present as a few large white patches, and globose to subglobose basidiospores Q' $=1.03$ (Yang 1997).

\section{Key to the species of Amanita sect. Vaginatae from northern Thailand}

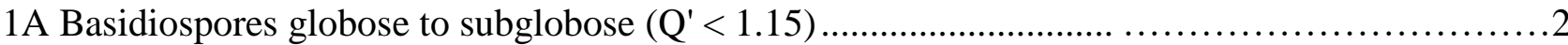

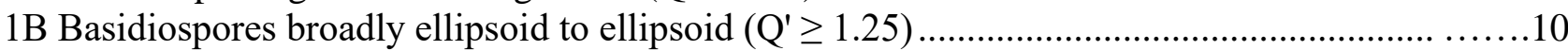

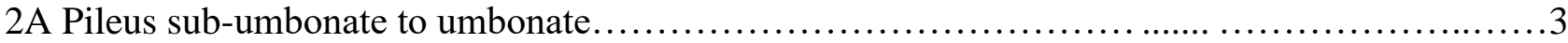

2B Pileus shape various but not umbonate, often depressed at center ........................................... 4 3A Pileus with exceptionally large darkly colored central disc contrasting abruptly with a paler margin, brownish black, fibrillose or squamules stipe not forming distinctive banded pattern, striations length $=0.33-0.42 \mathrm{R}$

A. brunneoumbonata

3B Pileus with small colored central disc or one not contrasting abruptly in color with the margin, greyish brown, fibrils or squamules on stipe forming distinctive banded pattern, striations length $=$ $0.18-0.21 \mathrm{R}$.

A. brunneoprocera

4A Incomplete saccate volva (pileus brown, occasionally covered with a greyish white, large universal veil patch, striations length $=0.44-0.46 \mathrm{R}, \mathrm{Q}=(1.00-)$ 1.01-1.12 (1.14), $\mathrm{Q}^{\prime}=$

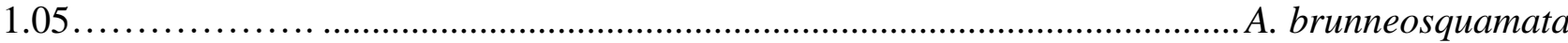

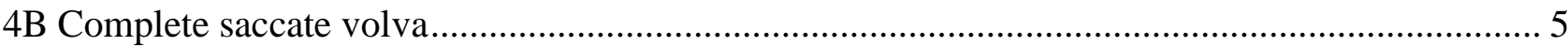

$5 \mathrm{~A}$ Color at center contrasting abruptly with paler colors at the margin ......................................... 6

5B Color at center not contrasting abruptly with paler colors at the margin.................................. 7

6A Pileus cinnamon, caramel brown or brown, squamules on stipe forming a distinctive banded pattern, presence of warts on the general veil which are at least in part colored as the pileipellis and stipe bands, distinct lamellar edge, caramel brown, striations length $=0.45-0.46 \mathrm{R}, \mathrm{Q}=(1.0-)$ $1.02-1.14(-1.16) \mathrm{Q}^{\prime}=1.09$

A. cinnamomea 6B Pileus smoke brown, squamules on stipe not forming a distinctive banded pattern, striations

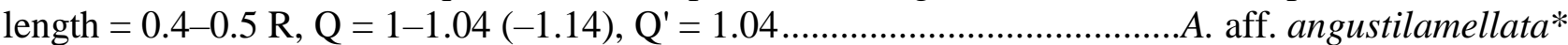
7A Universal veil remnants present on pileus (universal veil remnants composed of light yellowish grey, floccose, slightly shaggy patches, pileus yellow to yellowish gray, striations relatively short, $\left.0.14 \mathrm{R}, \mathrm{Q}=1.0-1.08, \mathrm{Q}^{\prime}=1.04\right)$ A. luteoparva

7B Universal veil remnants usually lacking on pileus.

$8 \mathrm{~A} \mathrm{Q}^{\prime} \geq 1.08$, pileus orange brown to fulvous orange or yellow (distinct lamellar edge orang- brown colored, upper part of volva colored brownish orange; striations length $=0.33-0.4 \mathrm{R}, \mathrm{Q}=1.01-$ $1.13(-1.16)$ A. suborientifulva

$8 \mathrm{~B} \mathrm{Q}^{\prime} \leq 1.08$, pileus dull yellow to yellowish grey white.

$9 \mathrm{~A} \mathrm{Q}^{\prime}=1.0$, pileus yellowish grey, lighter at disc, with margin striations length $=0.21-0.24 \mathrm{R}$, outer surface of universal veil on stipe base grayish yellow, $\mathrm{Q}=1.0-1.1$................... flavidogrisea $9 \mathrm{~B} \mathrm{Q}^{\prime}=1.04$; pileus yellow to yellowish orange, darker at disc, with margin striations length = $0.25-0.28 \mathrm{R}$, outer surface of universal veil on stipe base white, $\mathrm{Q}=1.0-1.12(-1.18)$ 
10A Universal veil remnants present on pileus (pileus ash-grey, covered with white, membranous universal veil remnants, striations length $=0.3-0.5 \mathrm{R}, \mathrm{Q}=(1.09-)$ 1.15-1.37 (-1.7), $\mathrm{Q}^{\prime}=$ 1.3 . A. ovalispora*

10B Universal veil remnants usually lacking on pileus.

11A Squamules on stipe forming a strongly banded pattern; pileus white, tomentose to farinose, with striations length $=0.25 \mathrm{R}, \mathrm{Q}=(1.25-) 1.27-1.65(-1.74), \mathrm{Q}^{\prime}=1.46$ A. pudibunda* 11B Squamules on stipe not forming strongly banded pattern; pileus dark grey, surface minutely silky, with striations length $=0.36-0.4 \mathrm{R}, \mathrm{Q}=(1.01-) 1.02-1.14(-1.16), \mathrm{Q}^{\prime}=1.25$.

A. subovalispora

*based on the description in Sanmee et al. (2008) of specimens collected in northern Thailand.

\section{Discussion}

Recent studies of mushroom diversity in the forests of northern Thailand have documented a great number of new species as well as new distribution records of known species (Wisitrassameewong et al. 2015, Chen et al. 2016, Li et al. 2016, Raspé et al. 2016, Thongbai et al. 2016, 2017). The present study is part of an inventorisation of Amanita in Thailand, over a fiveyear period (2012-2016). As a result, the number of Amanita species from various sections, both new to science or new to Thailand has dramatically increased. This study dealt with sect. Vaginatae and, remarkably, all specimens studied belong to nine new species, confirming that the diversity of Amanita in Thailand is high, with likely many more remaining undescribed. The subgenus Amanita includes three sections; sect. Vaginatae contains the highest number of taxa, approximately 281 worldwide, whereas sect. Amanita includes 150 taxa and sect. Caesareae is comprised of 89 taxa (www.amanitaceae.org/?subgenus+Amanita Tulloss, Tulloss \& Yang 2018). To date, the diversity of Amanita in subg. Amanita collected from Thailand closely reflects the infrageneric diversity of this subgenus found worldwide, with twelve in sect. Vaginatae, six in sect. Amanita, and three in sect. Caesareae (Sanmee et al. 2008, Li et al. 2016, Thongbai et al. 2016). However, SánchezRamírez et al. (2015) reported several undescribed species in sect. Caesareae from Thailand.

Amanita sect. Vaginatae has traditionally been classified based on macro-morphological features such as pileus colors, decoration of the stipe, attachment of the volva, and structure of the universal veil on the pileus or stipe base, as well as micro-morphological features such as the size and shape of spores (Bas 1977, Tulloss 1994, Neville \& Poumarat 2009). Many of these characteristics are highly labile and cannot be satisfactorily observed in dried herbarium specimens, and a great deal of important information can be lost from poorly collected and conserved specimens. While this can also be said for many fleshy mushrooms, in our experience it is particularly true for Amanita sect. Vaginatae. It is therefore critical to have full descriptions and notes from the field, e.g. color, volva, and universal veil remnants. Good photographs are also necessary. Especially noteworthy characteristics observed in Thai collections studied here include the saccate volva with incomplete belt of A. brunneosquamata, the striking dark radially fibrillose pileus of $A$. brunneoumbonata, broadly ellipsoid to ellipsoid basidiospores of $A$. subovalispora, the partly orange warts on the volva and deeply colored lamellar edge of A. cinnamomea, the waxy dull yellow pileus of $A$. flavidocerea, the large saccate volva conspicuously free from the stipe base of A. flavidogrisea, the tightly adherent universal veil remnants of A. luteoparva, and the very striking orange color of A. suborientifulva.

This investigation included a combination of morphological methods and DNA analyses of not only the nrITS region (including 5.8S) and nrLSU, but also the protein-coding genes $\beta$-tubulin and $r p b 2$. Section Vaginatae is still relatively poorly known from a molecular perspective, as most analyses have been based on only nrITS or nrLSU (Tang et al. 2015). However, nrITS or nrLSU initial BLAST searches of both nrLSU and ITS1+5.8S+ITS2 sequences we produced show mostly low percent similarity with sequences data available from GenBank, and those sequences were excluded from the present phylogenetic analyses. The phylogenetic diversity seems to be higher 
among Thai species than among temperate species, in both the two-gene and four-gene analyses likely showing that Amanita sect. Vaginatae is more diverse in tropical Asia due to higher rates of speciation, as was observed for section Caesareae (Sánchez-Ramírez et al. 2015). Several unique clades comprised solely of Thai collections were indeed found in addition to the clades including species from Europe and USA. For example, A. cinnamomea and A. brunneosquamata are sister taxa forming a supported clade. Moreover, three species, Amanita subovalispora, A. flavidocerea, and A. brunneoprocera were isolated outside the smallest well-supported clade comprising all European species. Finally, the branches leading to Thai species are clearly longer than the branches leading to European species, with the exception of A. brunneoumbonata and A. suborientifulva. The latter two species are sister to European species, A. magnivolvata and A. fulva, respectively, with high bootstrap support.

Based on correlational analysis between shape and size of spores Amanita specimens from both the Western Hemisphere and East Asian regions, including Japan, India, Pakistan, Singapore, and southwestern China and latitude and habitat, Tulloss (2005) found that spores are smaller in forests dominated at least locally by non-ectomycorrhizal trees compared to areas with a high diversity of ectomycorrhizal tree hosts, even when the areas are adjacent to each other $\left(95^{\text {th }}\right.$ percentile of length of available data recorded spore length less than $8.3 \mu \mathrm{m}$ ). The same author hypothesized that in high diversity lowland tropical forests with mostly non-ectomycorrhizal trees, the smaller spores may be an adaptation to increase dispersal and germination near widely scattered ectomycorrhizal trees individuals. His study did not include any specimen from Thailand. Interestingly, all nine newly described species in the present study have relatively large spores with the $95^{\text {th }}$ percentile of length over $8.3 \mu \mathrm{m}$, with A. luteoparva having the minimum $(8.9 \mu \mathrm{m})$ and $A$. cinnamomea the maximum $(12.5 \mu \mathrm{m})$. These findings are consistent with the hypothesis put forward by Tulloss (2005) in that the forests where all of the Thai collections were made would be considered upland forests dominated by ectomycorrhizal tree species in the Fagaceae (Castanopsis, Lithocarpus, and Quercus) and/or Dipterocarpaceae (Dipterocarpus spp. and Shorea spp.). However, careful analyses of spore size and ecological data taking phylogenetic relationships into account are needed to test Tulloss (2005) hypothesis.

\section{Acknowledgements}

The help of Dr. Shaun Pennycook, Prof. Dr. Marc Stadler, Dr. André Fraiture, Wim Baert, Alexia Semeraro, and Myriam de Haan is greatly appreciated. BT is grateful to the Thai Royal Golden Ph.D. Jubilee-Industry (RGJ) program (Ph.D/0138/2553 in 4.S.MF/53/A.3). OR is grateful to the National Research Council of Thailand for permission to conduct research in Thailand. SL and OR acknowledge Thailand Research Fund for funding (TRF Research Team Association grant 588006) and the National Parks authorities for granting the permit for collecting in Doi Suthep-Pui National Park.

\section{References}

Aalto M. 1974 - Amanita magnivolvata sp. nova (Agaricales). Karstenia 14, 93-96.

Bas C. 1977 - Species concept in Amanita sect. Vaginatae I. In: Clémençon H (Ed.) The species concept in Hymenomycetes. Bibliotheca Mycologica 61, 79-103.

Bataille F. 1910 - Champignons rares ou nouveaux de la Franche-Comté. Bulletin de la Société Mycologique de France 26, 138-149.

Boedijn KB. 1951 - Notes on Indonesian fungi. The genus Amanita. Sydowia 5, 317-327.

Cai Q, Tulloss RE, Tang L, Tolgor B et al. 2014 - Multi-locus phylogeny of lethal Amanitas: implications for species diversity and historical biogeography. BMC Evolutionary Biology $14,1-16$.

Castresana J. 2000 - Selection of conserved blocks from multiple alignments for their use in phylogenetic analysis. Molecular Biology and Evolution 17, 540-552. 
Chen J, Moinard M, Xu J, Wang S et al. 2016 - Genetic analyses of the internal transcribed spacer sequences suggest introgression and duplication in the medicinal mushroom Agaricus subrufescens. Plos One 11, 1-15.

Corner EJH, Bas C. 1962 - The genus Amanita in Singapore and Malaya. Persoonia 2, 241-304.

Drehmel D, Moncalvo JM, Vilgalys R. 1999 - Molecular phylogeny of Amanita based on largesubunit of ribosomal DNA sequences: implications for taxonomy and character evolution. Mycologia 91, 610-618.

Doyle JJ, Doyle JL. 1990 - Isolation of plant DNA from fresh tissue. Focus 12, 13-15.

Fries EM. 1815 - Observationes mycologicae 1, 1-230.

Greville RK. 1822 - Scottish Cryptogamic Flora 1. pp. 18.

Hall TA. 1999 - BioEdit: a user-friendly biological sequence alignment editor and analysis program for Windows 95/98/NT. Nucleic Acids Symposium Series 41, 95-98.

Jayasiri SC, Hyde KD, Ariyawansa HA, Bhat J et al. 2015 - The faces of fungi database: fungal names linked with morphology, phylogeny and human impacts. Fungal Diversity 74, 3-18.

Katoh K, Kuma K, Toh H, Miyata T. 2005 - MAFFT version 5: improvement in accuracy of multiple sequence alignment. Nucleic Acids Research 33, 511-518.

Kornerup A, Wanscher JH. 1978 - Methuen Handbook of Colour. 3rd edn. London: Eyre Methuen.

Kranabetter JM, Friesen J, Gamiet S, Kroeger P. 2009 - Epigeous fruiting bodies of ectomycorrhizal fungi as indicators of soil fertility and associated nitrogen status of boreal forests. Mycorrhiza 19, 535-548.

Li GJ, Hyde KD, Zhao RL, Hongsanan S et al. 2016 - Fungal diversity notes 253-366: taxonomic and phylogenetic contributions to fungal taxa. Fungal Diversity 78, 1-237.

Malysheva EF, Kovalenko AE. 2015 - Fungi of the Russian Far East. 4. Contribution to the study of Amanita sect. Vaginatae in the central Sikhote-Alin. Mikologiya i Fitopatologiya 149, 151163.

Nagasawa E, Hongo T. 1984 - New taxa of Amanita: Three new species and one new form from western Japan. Transactions of the Mycological Society of Japan 25, 367-376.

Neville P, Poumarat S. 2009 - Quelques espèces nouvelles ou mal délimitées d'Amanita de la soussection Vaginatinae. 1er complément à Amaniteae, Fungi Europaei 9. Fungi non Delineati 51-52, 1-200.

Miller MA, Holder MT, Vos R, Midford PE et al. 2009 - The CIPRES portals. Available from: http://www.phylo.org/portal2/home. (Accessed December 2017).

Posada D. 2008 - jModelTest: Phylogenetic model averaging. Molecular Biology and Evolution $25,1253-1256$.

Rambaut A. 2009 - FigTree. Available from: http://tree.bio.ed.ac.uk/ (accessed December 2013).

Raspé O, Vadthanarat S, De Kesel A, Degreef J et al. 2016 - Pulveroboletus fragrans, a new Boletaceae species from Northern Thailand, with a remarkable aromatic odour. Mycological Progress 15, 38 .

Rodríguez-Caycedo C, Goldman N, Tulloss RE. 2018 - nrITS sublocus terminal motifs in the Amanitaceae. Studies in the Amanitaceae; Available from http://www.amanitaceae.org?nrITS+Sublocus+Termini+in+the+Amanitaceae (Accessed December 2018).

Ronquist F, Teslenko M, van der Mark P, Ayres D et al. 2011 - MrBayes 3.2: Efficient Bayesian phylogenetic inference and model choice across a large model space. Systematic Biology 61, 539-542.

Sánchez-Ramírez S, Tulloss RE, Amalfi M, Moncalvo JM. 2015 - Palaeotropical origins, boreotropical distribution and increased rates of diversification in a clade of edible ectomycorrhizal mushrooms (Amanita section Caesareae). Journal of Biogeography 42, 351363.

Sanmee R, Tulloss RE, Lumyong P, Dell B, Lumyong S. 2008 - Studies on Amanita (Basidiomycetes: Amanitaceae) in Northern Thailand. Fungal Diversity 3, 97-123. 
Singer R. 1963 - Oak mycorrhiza fungi in Colombia. Mycopathologia et Mycologia Applicata 20, 239-250.

Singer R. 1949 - The Agaricales in modern taxonomy. Lilloa 22, 1-832.

Stamatakis A. 2014 - RAxML Version 8: A tool for phylogenetic analysis and post-analysis of large phylogenies. Bioinformatics 10.1093/bioinformatics/btu033; Available from: http://bioinformatics.oxfordjournals.org/content/early/2014/01/21/bioinformatics.btu033.abs tract. (Accessed December 2018).

Tang LP, Cai Q, Lee S, Buyck B et al. 2015 - Taxonomy and phylogenetic position of species of Amanita sect. Vaginatae s.l. from tropical Africa. Mycological Progress 14, 1-15.

Thiers B. 2017 - Index Herbariorum: A global directory of public herbaria and associated staff. New York Botanical Garden's Virtual Herbarium; Available from www. sweetgum.nybg.org/science/ih/. (Accessed December 2018).

Thongbai B, Miller SL, Stadler M, Wittstein K et al. 2017 - Study of three interesting Amanita species from Thailand: Morphology, multiple-gene phylogeny and toxin analysis. Plos One $12,1-25$.

Thongbai B, Tulloss RE, Miller SL, Hyde KD et al. 2016 - A new species and four new records of Amanita (Amanitaceae; Basidiomycota) from Northern Thailand. Phytotaxa 286, 211-231.

Tulloss RE. 1994 - Type studies in Amanita section Vaginatae I: some taxa described in this century (studies 1-23) with notes on description of spores and refractive hyphae in Amanita. Mycotaxon 52, 305-396.

Tulloss RE. 2000 - Nomenclatural changes in Amanita. Mycotaxon 75, 329-332.

Tulloss RE. 2005 - Amanita distribution in the Americas with comparison to eastern and southern Asia and notes on spore character variation with latitude and ecology. Mycotaxon 93, 189231.

Tulloss RE. 2018 - Biometric variables: meanings and how to define a range. Studies in the Amanitaceae; Available from: www.amanitaceae.org/?How To's\&howto=8. (Accessed December 2018).

Tulloss RE, Moses E. 1995 - Amanita populiphila - a new species from the Central United States. Mycotaxon 53, 455-466.

Tulloss RE, Ovrebo CL, Halling RE. 1992 - Studies on Amanita (Amanitaceae) from Andean Colombia. Memoirs of the New York Botanical Garden 66, 1-46.

Tulloss RE, Yang ZL. 2018 Amanitaceae studies; Available from: www.amanitaceae.org. (Accessed December 2018).

Weiß M, Yang ZL, Oberwinkler F. 1998 - Molecular phylogenetic studies in the genus Amanita. Canadian Journal of Botany 76, 1170-1179.

Wisitrassameewong K, Nuytinck J, Le HT, De Crop E et al. 2015 - Lactarius subgenus Russularia (Russulaceae) in South-East Asia: 3. New diversity in Thailand and Vietnam. Phytotaxa 207, 215-241.

Wolfe BE, Tulloss RE, Pringle A. 2012 - The irreversible loss of a decomposition pathway marks the single origin of an ectomycorrhizal symbiosis. Plos One 7, 1-9.

Yang ZL. 1997 - Die Amanita-Arten von Südwestchina. Bibliotheca Mycologica 170, 1-240.

Yang ZL. 2004 - Two new species of Amanita (Basidiomycota) from China. In: Agerer R, Piepenbring M, Blanz P (eds) Frontiers in basidiomycote mycology. IHW-Verlag, Eching, pp 315-324.

Yang ZL, Weiss M, Oberwinkler F. 2004 - New species of Amanita from the eastern Himalaya and adjacent regions. Mycologia 96, 636-646.

Zhang L, Yang J, Yang ZL. 2004 - Molecular phylogeny of eastern Asian species of Amanita (Agaricales, Basidiomycota): Taxonomic and biogeographic implications. Fungal Diversity 17, 219-238. 